Research Article

\title{
Experimental Study on Coal Permeability Variation during Microwave Radiation
}

\author{
Yulin Ma $\left(\mathbb{D},{ }^{1}\right.$ Yao Cheng, ${ }^{2}$ Wenlong Shang, ${ }^{1}$ Dong Zhao $\left(\mathbb{D},{ }^{3}\right.$ and Xianggang Duan ${ }^{4}$ \\ ${ }^{1}$ School of Mechanics and Engineering, Liaoning Technical University, Fuxin 123000, China \\ ${ }^{2}$ College of Innovation and Practice, Liaoning Technical University, Fuxin 123000, China \\ ${ }^{3}$ College of Safety and Emergency Management Engineering, Taiyuan University of Technology, Taiyuan 030024, China \\ ${ }^{4}$ Petro China Research Institute of Petroleum Explorations and Development, Beijing 100083, China \\ Correspondence should be addressed to Yulin Ma; hxwyaoyao@163.com
}

Received 24 August 2019; Revised 3 January 2020; Accepted 17 January 2020; Published 24 February 2020

Academic Editor: Antonio Riveiro

Copyright (C) 2020 Yulin Ma et al. This is an open access article distributed under the Creative Commons Attribution License, which permits unrestricted use, distribution, and reproduction in any medium, provided the original work is properly cited.

\begin{abstract}
Coal-bed methane (CBM) is a new type of clean energy, which is abundant in China. Rational development and use of CBM can not only reduce the occurrence of mine disasters but also alleviate energy shortages. However, the "high storage capacity and lowpermeability" characteristics of China's CBM have hindered the realization of industrialized CBM production. To study the effect of microwave radiation on the permeability of coal reservoirs, a seepage experiment under different stress and microwave radiation conditions was carried out by using the seepage experiment system of gas-bearing coal under microwave radiation developed by the authors. The relationship among different microwave powers, different irradiation times, different energy inputs, and coal permeability was explored. The results show that the microwave power effect and the temperature effect promote coal permeability. Under microwave radiation, the relationship between permeability and effective stress followed a negative exponential function, and all R-squared values were greater than 0.97 . The permeability increased monotonically with increasing microwave power and irradiation time, and the linear fitting slope of the rate of increase in the low-effective-stress area was greater than in the high-effective-stress area. Under the same energy input, permeability increased with rising microwave power. The peak temperature of the coal sample also increased with increasing power. When the microwave power increased to a certain range, the permeability growth of the coal sample was the greatest, and the temperature gradient of the coal-sample temperature field was the steepest. The coal sample experienced the optimum microwave radiation power under the action of microwaves to achieve the permeability enhancement effect of microwaves on the coal sample. The experimental results provide a theoretical reference for applying microwave radiation technology in coal-bed methane extraction.
\end{abstract}

\section{Introduction}

Energy is the basis of economic and social development and also the main factor affecting such development. With continuous development of the economy and society, the restriction of energy on economic and social development is becoming more and more severe. CBM is an important unconventional natural gas resource, and China is rich in CBM resources. The latest national CBM resource evaluation results show that the shallow CBM resource with a depth of $2000 \mathrm{~m}$ in China is $30.05 \times 10^{12} \mathrm{~m}^{3}$ and the recoverable CBM resource is $12.51 \times 10^{12} \mathrm{~m}^{3}[1,2]$. As a byproduct of coal resource extraction, CBM has two opposing aspects. On the one hand, it is a harmful gas, which is not only a major hidden danger in coal production but also an extremely powerful greenhouse gas. On the other hand, CBM is a kind of green energy, which could be an important alternative energy source for China's energy development. Realizing the industrialized utilization of CBM to reduce coal mine gas accidents, mitigate the greenhouse effect, reduce air pollution, and support the energy supply of China would be of great significance. So far, China has achieved industrialized production of coal-bed methane in some CBM storage areas, but there is still a certain gap between China and other countries such as the United States. The reason for this is that in the special geological environment in China, the pore 
structure of coal-bed methane reservoirs is complex, and most of them have high storage capacity and low permeability, making it difficult to achieve desorption and migration of coal-bed methane $[3,4]$ and imposing certain obstacles to achieving high-efficiency CBM output. Therefore, to achieve industrialized development of CBM, it is necessary to find an effective means of promoting its displacement and increasing its permeability.

To develop coal-bed methane in low-permeability coal seams, researchers in China and elsewhere have carried out many research studies and achieved a certain number of results. Over the years, many researchers in China and around the world have carried out theoretical explorations and experimental research. At present, the following methods are commonly used both in China and elsewhere: fracturing and stimulation technology, heat injection and stimulation technology, multiple gas displacement technology, acoustic shock methods, and microbial stimulation technology. Ai et al. [5] studied the connection between the pressure fracture network generated by hydraulic fracturing and the original structure of coal reservoirs and fundamentally defined the stimulation mechanism of coal-bed gas produced by hydraulic fracturing. Dong et al. [6-9] studied the effect of hydraulic fracturing on coal-bed methane wells. Fang et al. [10] analyzed the feasibility of multi-gas displacement technology for coal-bed methane through theoretical analysis. The results showed that it is feasible to use gas displacement technology to extract coal-bed methane from low-permeability reservoirs in China. Wu et al. [11] studied the change rules of permeability and mechanical strength of coal rocks after carbon dioxide displacement of gas in coal by designing a triaxial adsorption-desorption seepage experiment. Zhao et al. [12, 13] designed experiments to study the splitting effect of ultrasonic waves of different power on coal and rock. It was found that increasing ultrasonic power led to increases in the cracking effect and in coal permeability. Jiang et al. [14] studied the desorption and diffusion characteristics of CBM under the action of a sound field and defined the desorption and diffusion characteristics of CBM under different sound-field conditions. Feng et al. [15], in a study of the reasonable thermal injection temperature range for heat injection to extract coal-bed gas, finally determined through experimental research a reasonable thermal injection temperature for coal-bed methane extraction by thermal injection into a low-permeability coal reservoir. Zhang et al. [16] simulated and studied the process of coal-bed gas exploitation by thermal injection into a low-permeability coal reservoir by developing a thermal-fluid-solid multiphysical field-coupling model and obtained the seepage and migration laws of coal-bed gas in the process of thermal injection and mining. Li et al. [17] studied the effect of carbon dioxide temperature on CBM displacement and stimulation by combining injection and heat-recovery technology with gas displacement technology and determined the relationship between the temperature of injected displacement gas and reservoir permeability.

Above all, to achieve industrialized production of CBM, it is urgent to combine the research results of scientists around the world to develop a method of promoting gas dissolution and increasing permeability that can improve China's special coal-reservoir structure. Microwave radiation has been widely used in other production fields such as coking, geotechnical engineering, oil extraction, and sewage treatment $[18,19]$. The key to coal-bed methane exploitation lies in promoting solution and increasing permeability. Microwave radiation is a kind of enhanced heat injection and extraction method. Compared with the heat conduction of conventional heating, the heating of coal by microwave radiation is considered to be a process in which high-frequency electromagnetic fields drive highfrequency oscillations of polar molecules inside coal rocks, and intense friction generates heat between molecules. Therefore, microwave radiation heats up rapidly and covers a wide range, which is conducive to the formation of coalbed methane desorption and seepage channels. As a kind of UHF electromagnetic wave, microwaves have a frequency of $2450 \mathrm{MHz}$. Microwave heating has the characteristics of immediacy, integrity, selectivity, high efficiency, and safety. The process of microwave heating is that polar molecules "stir" at the molecular level in the microwave magnetic field, so that their molecules collide with each other and generate heat by friction [20]. With the application of microwave heating technology to coal-bed methane extraction, many researchers worldwide have studied it. Hong et al. carried out a series of studies on the effect of microwaves on coal, studied the influence of microwaves on the fractal dimension of coal rocks through experimental research and theoretical analysis [21], used numerical simulation to establish geometric models under different microwave conditions [22], and studied the influence of microwave heating on coal samples under different microwave conditions. Changes in the physical properties of coal and rock after microwave treatment were studied and analyzed by designed experiments [23]. Other researchers have found that after microwave treatment, the inherent moisture of coal was significantly reduced, its calorific value and fixed carbon content were improved, and the original physical properties of the coal matrix were changed [24]. Some researchers in China have conducted experimental studies on the adsorption and desorption characteristics of gas in coal after microwave application and found that microwaves can promote desorption of coal-bed methane from coal $[25,26]$. Microwave heating is a heating body, in the process of the role of microwave electromagnetic field around the coal sample specimen, the coal sample specimen in microwave electromagnetic field to realize heating body, this way of role compared with the traditional heat transfer efficiency is higher, and the special body of coal sample specimen had a greater influence on the internal structure.

The state of knowledge of the effects of microwave radiation on CBM stimulation is gradually improving. Therefore, combined with the microwave radiation triaxial percolation system developed in this study, this paper describes an experimental study on the percolation characteristics of coal seams under the impact of microwave radiation. The test results have a certain reference value for 
application of microwave radiation to production of coalbed methane.

\section{Experimental}

2.1. Experimental System. An experimental system for gascontaining coal percolation under microwave radiation was developed. As shown in Figures 1 and 2, the system is composed of a microwave generator, a three-axis pressurization device, a gas measuring device, a manual oil pressure pump, and a high-pressure gas cylinder. The frequency of the microwave generator is $2.45 \mathrm{GHz}$. The microwaves are emitted by generator 19 and transmitted to the microwave induction terminal outside the triaxial instrument through waveguide 18 . Because polytetrafluoroethylene has no effect on microwave conduction, inner sleeve 17 is made of polytetrafluoroethylene material, which plays a sealing role. This means that the microwaves act directly on the coal through the waveguide, which avoids the effect of other factors on microwave conduction reducing the experimental error. The power of the microwave generator is variable and can be adjusted. Microwave irradiation time can also be set according to the target time. In this way, microwaves with different powers and different irradiation times can be applied to the coal.

2.2. Samples (Proximate Analysis). The coal sample was from Haizhou Coal Mine in Fuxin, Liaoning province. It was middle metamorphic coal sample and located in minus $580 \mathrm{~m}$ seam. Coal samples were crushed by a jaw crusher.

The experiment mainly studied the change rules of coal permeability under microwave radiation. To avoid the influence of heterogeneity in the original coal sample on the experimental results, a custom-made briquette was selected as the specimen in the experiment. The original coal sample was taken from the low-permeability gas mine in Fuxin, Liaoning Province. Newly exposed coal samples at the underground working face were sealed and transported back to the laboratory. The original coal samples were crushed by a jaw crusher, and the coal was screened to 60-80 mesh. The proportion of coal particles to rosin was $50: 1$. After the mixture was well mixed, a standard specimen of formed coal was pressed at a molding pressure of $100 \mathrm{MPa}$ using a 200-t experimental press. The prepared briquette samples were put into a constant-temperature chamber and dried for 36 hours at $353.15 \mathrm{~K}$ for backup use. The vitrinite reflectance of the raw coal was $6.28 \%$. An industrial analysis of the raw coal is shown in Table 1.

\subsection{Experimental Procedure}

(1) Take the prepared specimen and use the heatshrinkable tube to seal the specimen in plastic using the upper and lower pressure heads. Load the plasticsealed specimen into the triaxial apparatus and connect the experimental device. After the connection is completed, the tightness of the whole experimental system is tested.
(2) Test the tightness. Apply pressure to the specimen. To prevent the failure of specimens under uneven loading, the axial pressure and confining pressure are loaded alternately to the target pressure. Conduct a voltage stabilization test.

(3) After the axial pressure and confining pressure remain stable, open the $\mathrm{CO}_{2}$ high-pressure cylinder. By adjusting the pressure-regulating valve, inject a certain pore pressure of carbon dioxide gas. Pore pressure is adjusted from low to high. After the gas is injected, open the air outlet valve of the triaxial apparatus and use the drainage valve to measure the gas quantity.

(4) Turn on the microwave generator after the air output is stable. Set the target microwave power and irradiation time. Microwaves are introduced into the triaxial apparatus through the wave guide and a helical copper wire. A stable microwave magnetic field is formed in the triaxial apparatus to act on the coal sample.

(5) After microwaves have been applied to the coal sample, the air outlet rate changes. After the gas rate becomes stable, the average value of five groups of data measured by the drainage method is taken as the gas infiltration flow rate under this experimental condition, which is used to calculate the permeability of the coal sample.

(6) Reset the axial pressure, confining pressure, pore pressure, microwave power, and irradiation time and repeat steps $1-5$. The gas infiltration flow rate under the corresponding experimental conditions is obtained, and the permeability is calculated. The specific experimental parameters are shown in Table 2 .

\section{Results}

3.1. Experimental Data. In the experiments, a steady-state measurement method based on Darcy's law was used to determine permeability. The formula for determining the permeability of coal samples is

$$
k=\frac{2 P_{0} \mu L q_{\text {out }}}{A\left(P_{\text {in }}^{2}-P_{0}^{2}\right)},
$$

where $k$ is the permeability $\left(\mathrm{cm}^{2}\right) ; L$ is the length of the coal sample $(\mathrm{cm}) ; q_{\text {out }}$ is the gas flow rate $\left(\mathrm{cm}^{3} / \mathrm{s}\right) ; \mu$ is the dynamic viscosity coefficient of the gas $(\mathrm{Pa} \cdot \mathrm{s}) ; A$ is the crosssectional area of the coal sample $\left(\mathrm{cm}^{2}\right) ; P_{\text {in }}$ is the gas inlet pressure $(\mathrm{MPa})$; and $P_{0}$ is the standard atmospheric pressure (MPa).

The effective stress is an important factor affecting deformation of the coal sample. The mathematical tensor of the effective stress on the coal sample can be expressed as

$$
\sigma_{i j}^{\prime}=\sigma_{i j}-\alpha p \delta_{i j}
$$

where $\sigma_{i j}^{\prime}$ is the effective stress of the coal skeleton ( $\left.\mathrm{MPa}\right) ; \sigma_{i j}$ is the total pressure exerted on the coal skeleton ( $\mathrm{MPa}) ; \alpha$ is the equivalent coefficient related to the coal body, 


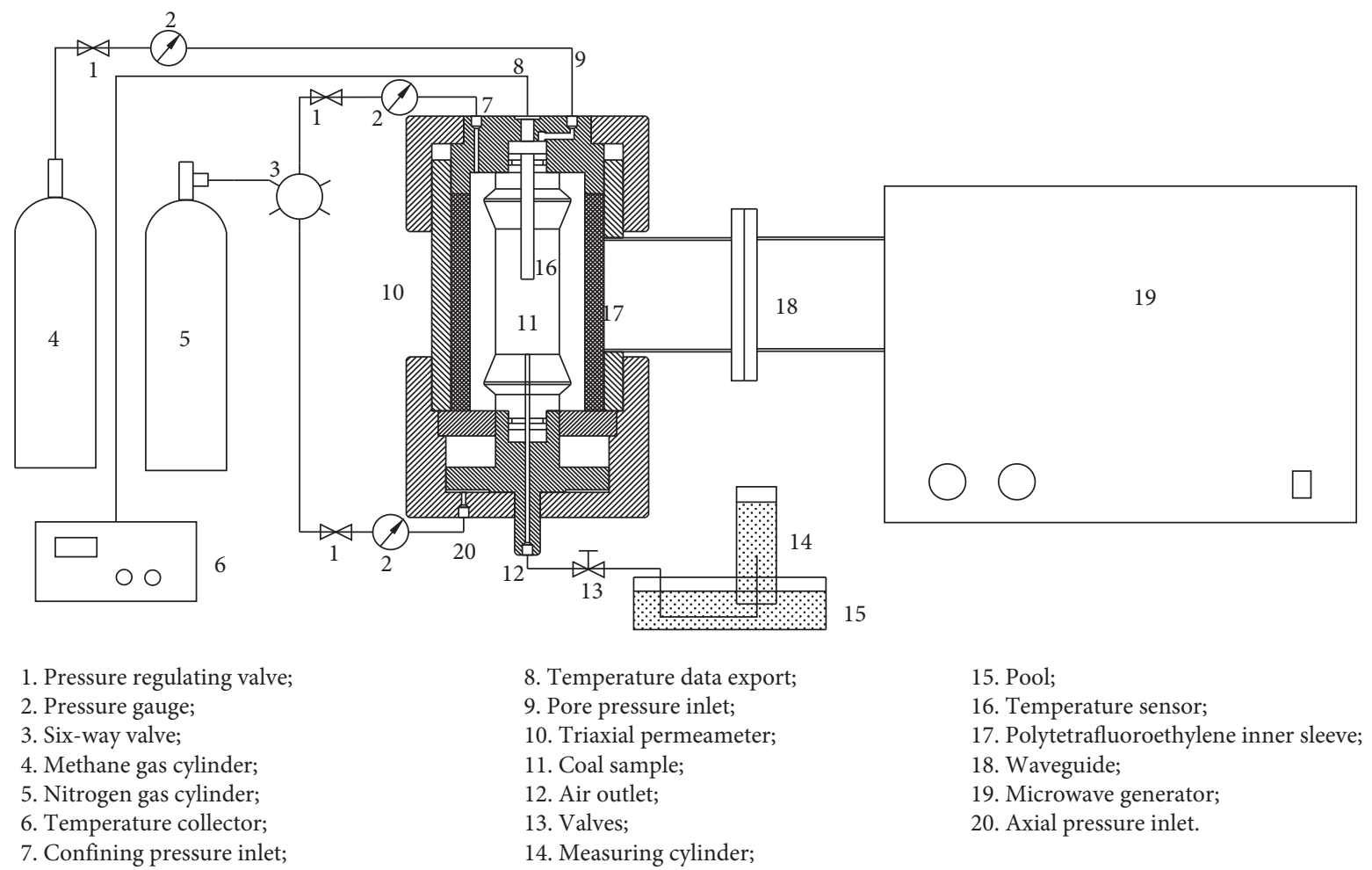

Figure 1: Schematic diagram of the experimental system.

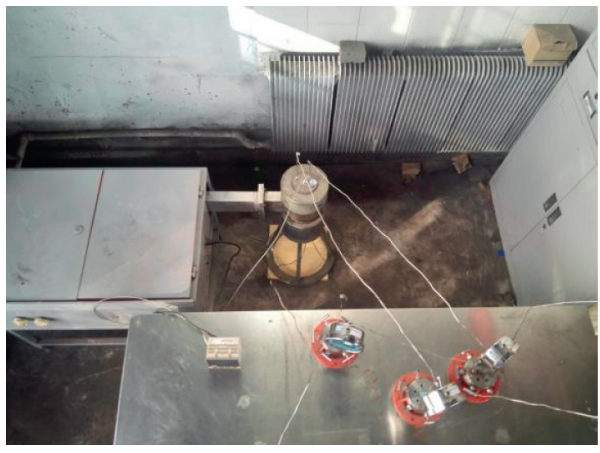

(a)

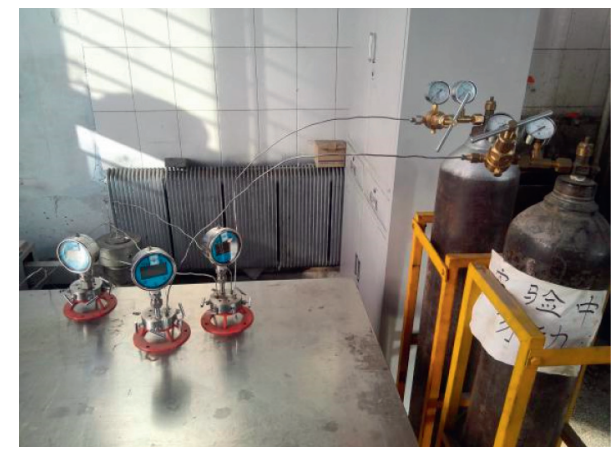

(b)

Figure 2: Physical drawing of the experimental device.

TABLE 1: Industrial analysis of coal samples.

\begin{tabular}{lcccc}
\hline Sample number & $M_{\mathrm{ad}}$ & $A_{\mathrm{d}}$ & $V_{\mathrm{daf}}$ & \\
\hline FX & 3.56 & 16.37 & 31.86 & $\mathrm{FC}_{\mathrm{ad}}$ \\
\hline
\end{tabular}

dimensionless, and $0<\alpha<1$ (to facilitate data processing, $\alpha$ is set to 1$) ; p$ is the pore pressure of the coal skeleton $(\mathrm{MPa})$; and $\delta_{i j}$ is a Kronecker symbol.

According to the experimental data obtained, the relationship between permeability and effective stress at microwave powers of $500 \mathrm{~W}, 1000 \mathrm{~W}$, and $1500 \mathrm{~W}$ and irradiation times of $1 \mathrm{~min}, 1.5 \mathrm{~min}$, and $3 \mathrm{~min}$ was obtained, and the fitting software was used to process the experimental data.
3.2. Effect of Microwave Irradiation Time on Coal Permeability. To explore the influence of microwave irradiation time on the permeability of coal seams, the variation trend of permeability with effective stress under the same microwave power, but different irradiation times was analyzed. The experimental data and fitting results are shown in Figures 3-5. These figures describe the change in coal permeability with effective stress under different microwave irradiation time conditions, given axial and confining 
TABLE 2: Experimental permeability measurement program.

\begin{tabular}{lcccc}
\hline $\begin{array}{l}\text { Irradiation time } \\
(\mathrm{min})\end{array}$ & $\begin{array}{c}\text { Microwave } \\
\text { power }(\mathrm{W})\end{array}$ & $\begin{array}{c}\text { Axial pressure, } \\
\text { confining pressure } \\
(\mathrm{MPa})\end{array}$ & $\begin{array}{c}\text { Effective } \\
\text { stress }(\mathrm{MPa})\end{array}$ & Experimental requirements \\
\hline $1,1.5,3$ & 3 & $0.5-2$ & $\begin{array}{c}\text { Measure the permeability of coal samples under different } \\
\text { stress conditions by changing the microwave action } \\
\text { conditions and then obtain the law of microwave osmosis } \\
\text { enhancement }\end{array}$ \\
\hline
\end{tabular}

pressures of $3 \mathrm{MPa}, 4 \mathrm{MPa}$, and $5 \mathrm{MPa}$ and microwave powers of $500 \mathrm{~W}, 1000 \mathrm{~W}, 1500 \mathrm{~W}$, and $2000 \mathrm{~W}$. The experimental data were fitted, and the results are shown by the curves.

The change curves of permeability with effective stress in Figures 3(a)-3(d) show that when a certain microwave power was selected, the permeability of the coal samples increased with longer irradiation time under the same stress state and that the increase in amplitude was particularly obvious in the low-effective-stress area. Figures 4 and 5 also display the same trend. Clearly, the permeability of the coal samples is positively correlated with microwave irradiation time, and the magnitude of the effective stress has an influence on the permeability enhancement effect of microwave radiation. The results of experimental data fitting for permeability and effective stress are shown in Figures 3-5, and the fitting results are shown in Tables $3-5 . R^{2}$ were all greater than 0.98 , with a very high quality of fit. Therefore, the relationship between permeability and effective stress under the same microwave power but different irradiation durations follows a monotonically decreasing exponential function.

The reasons for the increase in coal permeability after exposure to microwave radiation were analyzed. First, the integrity of microwave radiation heating makes it different from other heating methods such as electric heating. Through the effect of microwave radiation, the coal sample is placed in the microwave electromagnetic field, resulting in overall heating of the coal sample. Due to the complex mineral composition of the coal body and the differences in the dielectric constants and other parameters of various substances, the ability of various minerals to absorb microwave energy is different, resulting in different overall rates of temperature rise and uneven distribution of the temperature field in the coal body. Therefore, thermal stress is generated in the coal sample, and "tearing" is generated under the action of thermal stress, increasing the porosity of the coal sample. According to the stress sensitivities of coal and rock, the porosity increases and the permeability of the coal sample increases. Second, with longer irradiation time, the microwave energy input into the coal sample increased. The accumulated microwave energy rapidly increased the temperature of the coal sample. The rapid vaporization of residual bound water in the coal sample generated high pressure, resulting in expansion of some pore structures, an increase in the number of gas migration channels and an increase in coal sample permeability. Third, due to the characteristics of microwaves and temperature rise, gas molecular activity increased. A slippage effect became obvious during gas migration. A large number of adsorbed gas molecules were transformed into free states. The number of adsorbed gas molecules decreased, whereas the number of free molecules increased. Large quantities of gas molecules migrated out of the coal sample, and as a result, the macroscopic permeability of the coal sample increased.

As shown in Figures 3-5, the variation trend between permeability and effective stress was basically the same, and both of them satisfied the monotonically decreasing exponential function relation, but the permeability growth trend in the high- and low-effective-stress areas was different to some extent. The four data sets in Figure 5 were therefore analyzed further. When the effective stress was $0.5 \mathrm{MPa}$, the permeability increment was obviously greater than when the effective stress was $4 \mathrm{MPa}$. In other words, the permeability growth rate of the coal sample in the low-effective-stress area under the action of microwaves was greater than in the high-effective-stress area. The reasons are as follows: in the low-effective-stress area, with increasing microwave energy input, the internal stress of the coal sample increased, the stress generated became greater than the external constraint, and pores and cracks developed in the coal sample, leading to an increase in permeability. However, when the effective stress increased, the external constraint of the specimen was greater than the stress generated within the specimen, and expansion was restrained, resulting in slow permeability growth. It can be concluded that reducing the effective stress of a coal-bed methane reservoir is beneficial to microwave permeability enhancement in the actual mining process.

3.3. Effect of Microwave Power on Coal Permeability. To explore the influence of microwave power on coal seam permeability under the action of microwave radiation, the variation trend of permeability with effective stress under the same microwave power, but different irradiation times was analyzed. Experimental data and fitting results are shown in Figures 6-8. These figures describe the changes in coal permeability with effective stress under different microwave power conditions, with axial and confining pressures of $3 \mathrm{MPa}, 4 \mathrm{MPa}$, and $5 \mathrm{MPa}$ and microwave irradiation times of $1 \mathrm{~min}, 1.5 \mathrm{~min}$, and $3 \mathrm{~min}$. The experimental data were fitted, and the results are shown by the curves.

The change curves for permeability with effective stress in Figures 6(a)-6(c) show that when a different microwave power is selected to irradiate the coal sample for the same time under the same stress state, the permeability of the coal 

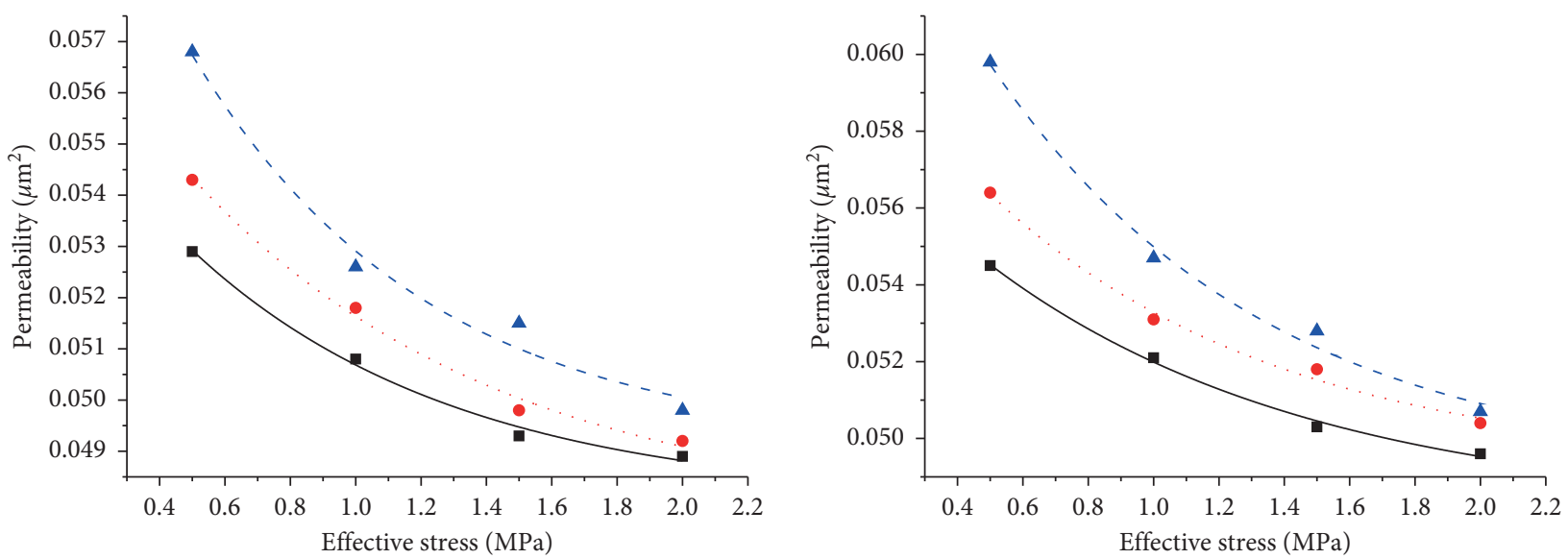

- $500 \mathrm{~W}$, microwave radiation $1 \mathrm{~min}$

- $500 \mathrm{~W}$, microwave radiation $1.5 \mathrm{~min}$

- $500 \mathrm{~W}$, microwave radiation $3 \mathrm{~min}$

- Fitting results of $1 \mathrm{~min}$

Fitting results of $1.5 \mathrm{~min}$

- - Fitting results of $3 \mathrm{~min}$

(a)

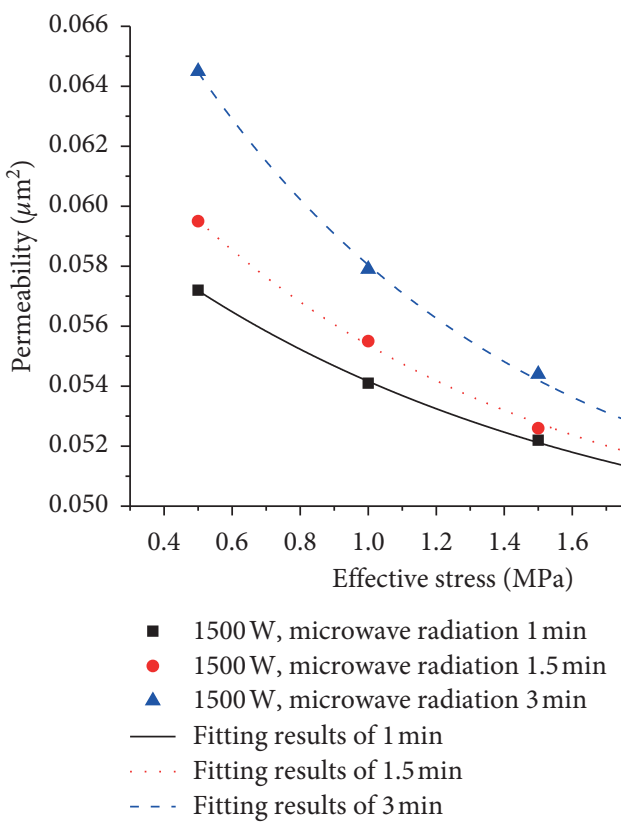

(c)
- $1000 \mathrm{~W}$, microwave radiation $1 \mathrm{~min}$

- $1000 \mathrm{~W}$, microwave radiation $1.5 \mathrm{~min}$

- $1000 \mathrm{~W}$, microwave radiation $3 \mathrm{~min}$

_ Fitting results of $1 \mathrm{~min}$

Fitting results of $1.5 \mathrm{~min}$

- - Fitting results of $3 \mathrm{~min}$

(b)

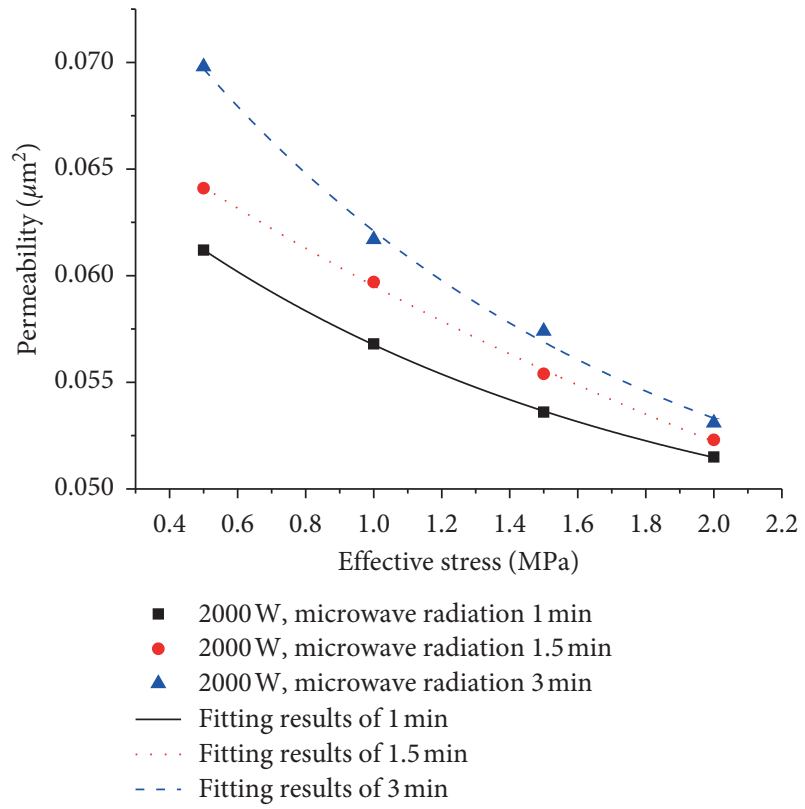

(d)

Figure 3: Changes in permeability with irradiation time at a confining pressure of $3 \mathrm{MPa}$.

sample increased as the selected microwave power increases, and the amplitude of the increase was particularly obvious in the low-effective-stress area. The changes in coal permeability under different confining pressures are shown in Figures 7 and 8 , which also display the same trend. The permeability of the coal sample was also positively correlated with the selected microwave power, and the effective stress had an impact on the permeability enhancement effect of microwave radiation. Hence, under the same irradiation time but different microwave power conditions, the relationship between permeability and effective stress follows a monotonically decreasing exponential function, and within a certain range, the permeability of coal samples is positively correlated with microwave power.

In this experiment, the greater the microwave power, the stronger was the electromagnetic field around the coal sample. The temperature gradient of the temperature field generated in the sample became steeper, and thermal stress increased accordingly, leading to destruction of the pore structure inside the sample. Secondary damage to the coal and rock mass was a side effect of further development of pore fissures. With increasing gas passage, the permeability of the coal sample increased. Under the same irradiation time and the same stress state, as microwave power 

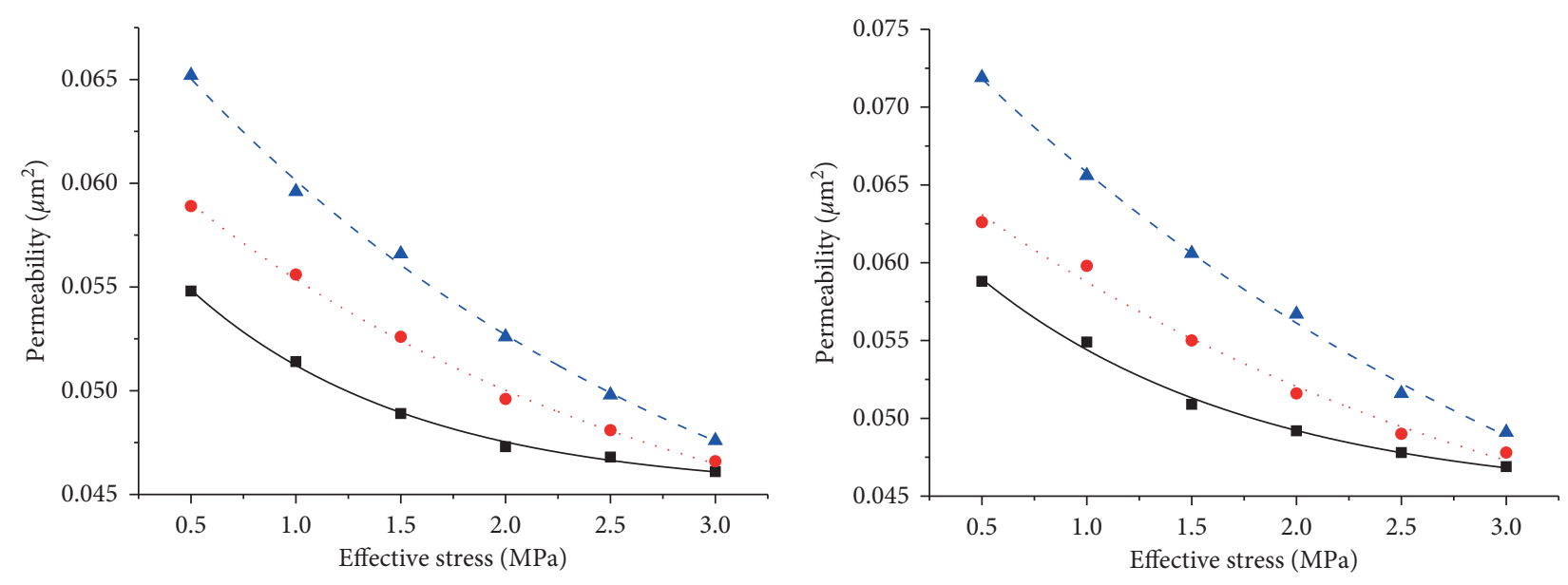

- $500 \mathrm{~W}$, microwave radiation $1 \mathrm{~min}$

- $500 \mathrm{~W}$, microwave radiation $1.5 \mathrm{~min}$

- $500 \mathrm{~W}$, microwave radiation $3 \mathrm{~min}$

_ Fitting results of $1 \mathrm{~min}$ Fitting results of $1.5 \mathrm{~min}$

- - Fitting results of $3 \mathrm{~min}$

(a)

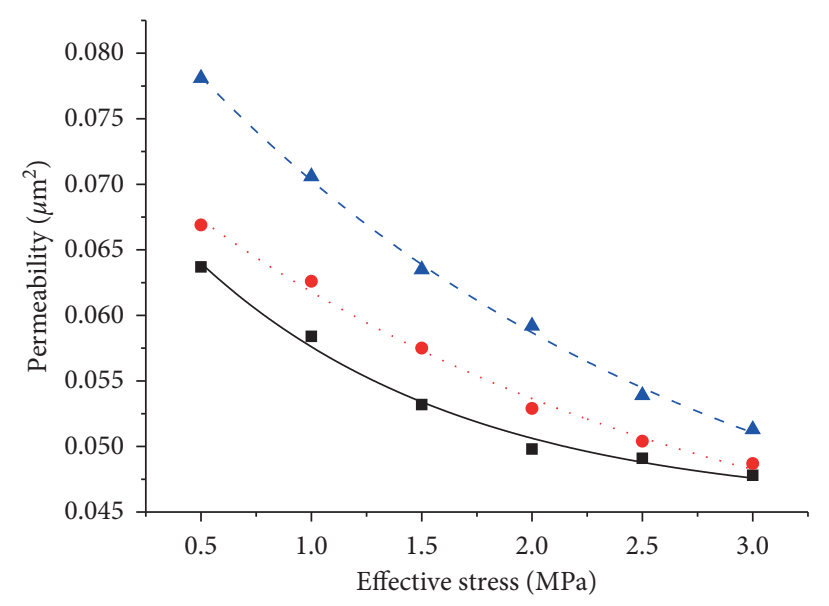

- $1500 \mathrm{~W}$, microwave radiation $1 \mathrm{~min}$

- $1500 \mathrm{~W}$, microwave radiation $1.5 \mathrm{~min}$

- $1500 \mathrm{~W}$, microwave radiation $3 \mathrm{~min}$

_ Fitting results of $1 \mathrm{~min}$

.... Fitting results of $1.5 \mathrm{~min}$

-. - Fitting results of $3 \mathrm{~min}$

(c)

- $1000 \mathrm{~W}$, microwave radiation $1 \mathrm{~min}$

- $1000 \mathrm{~W}$, microwave radiation $1.5 \mathrm{~min}$

- $1000 \mathrm{~W}$, microwave radiation $3 \mathrm{~min}$

_ Fitting results of $1 \mathrm{~min}$

Fitting results of $1.5 \mathrm{~min}$

- - - Fitting results of $3 \mathrm{~min}$

(b)

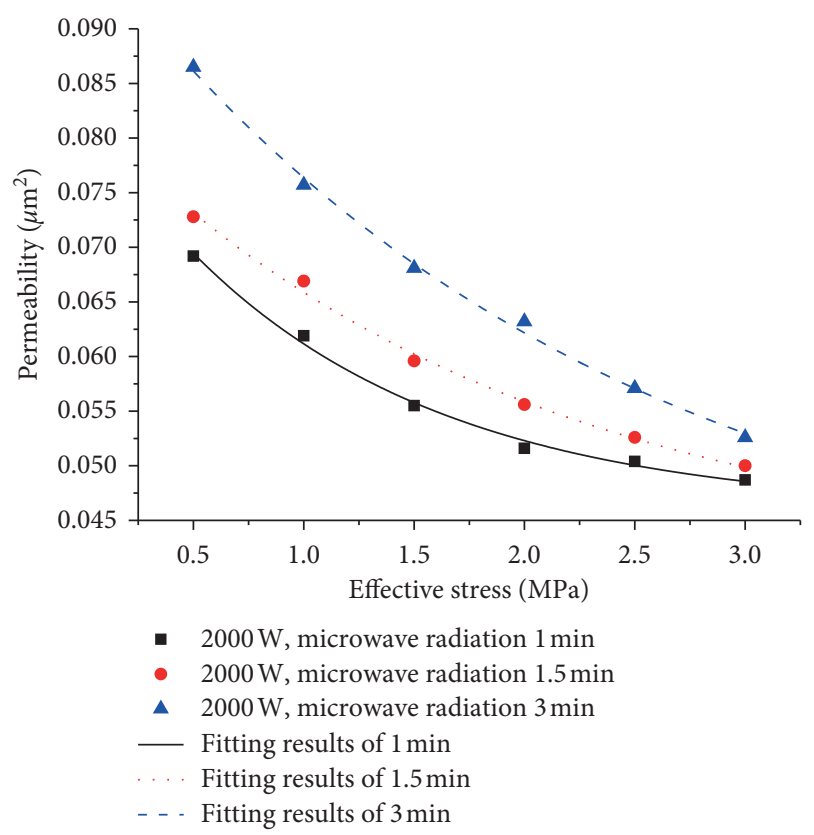

(d)

FIGURE 4: Changes in permeability with irradiation time at a confining pressure of $4 \mathrm{MPa}$.

increased, the energy transmitted by the microwave irradiation device to the coal sample also increased. The more energy that exists in the sample, the easier it is for gas molecules to obtain enough activation energy to transform into the free state. Under the action of microwaves, the gas has almost no adsorption capability, existing in a thin layer on the inner wall of the pore structure, which results in an obvious gas slippage effect and increased permeability of the coal sample.

Comprehensive analysis of Figures 6-8 reveals that the variation trend between permeability and effective stress was basically the same, both of them satisfied the monotonically decreasing exponential function, and permeability growth trends in the high- and low-effective-stress areas were different to some extent. In other words, under the action of microwaves, the permeability growth rate of the coal sample in the low-effective-stress area was greater than in the higheffective-stress area. The reasons are as follows: in the loweffective-stress area, with an increase in microwave energy input, the internal stress of the coal sample increased, the stress generated became greater than the external constraint, and pores and cracks developed in the coal sample, leading to an increase in permeability. However, when the effective stress increased, the external constraint of the specimen was 


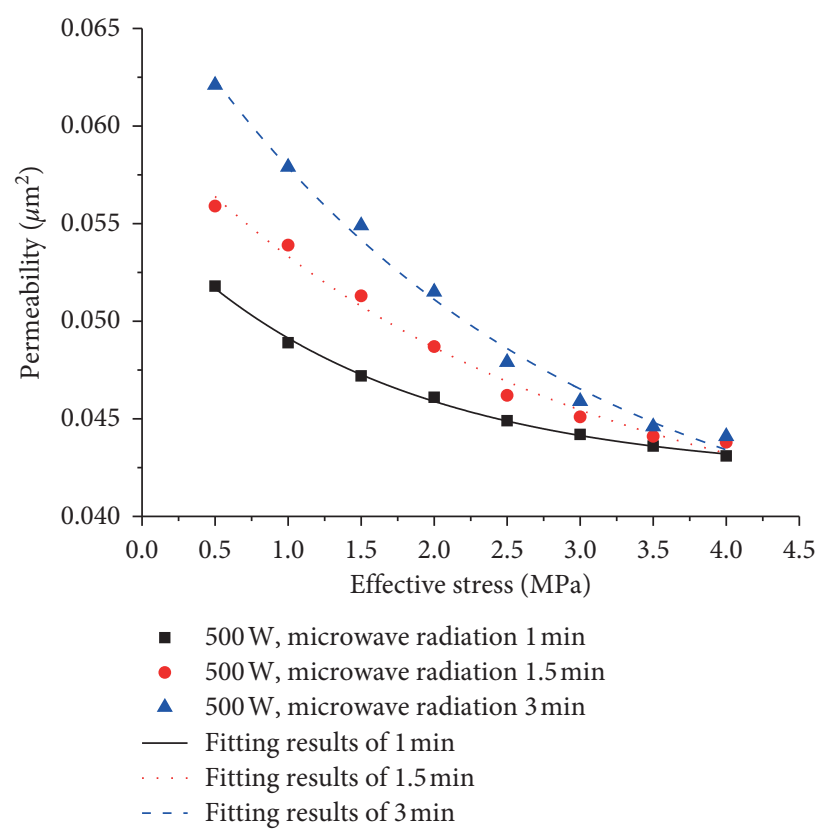

(a)

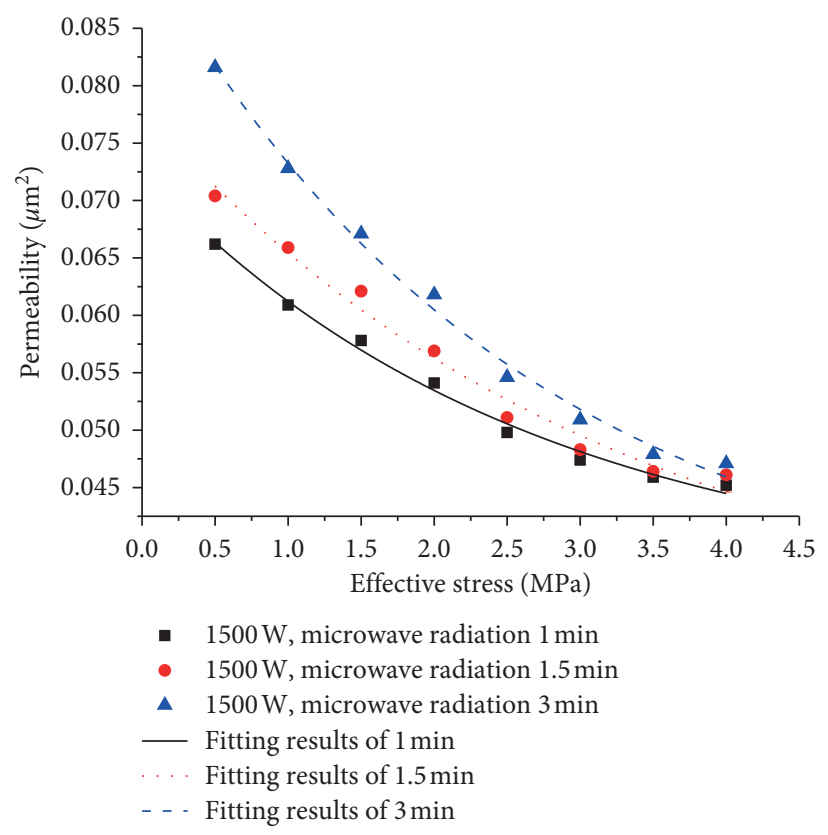

(c)



(b)

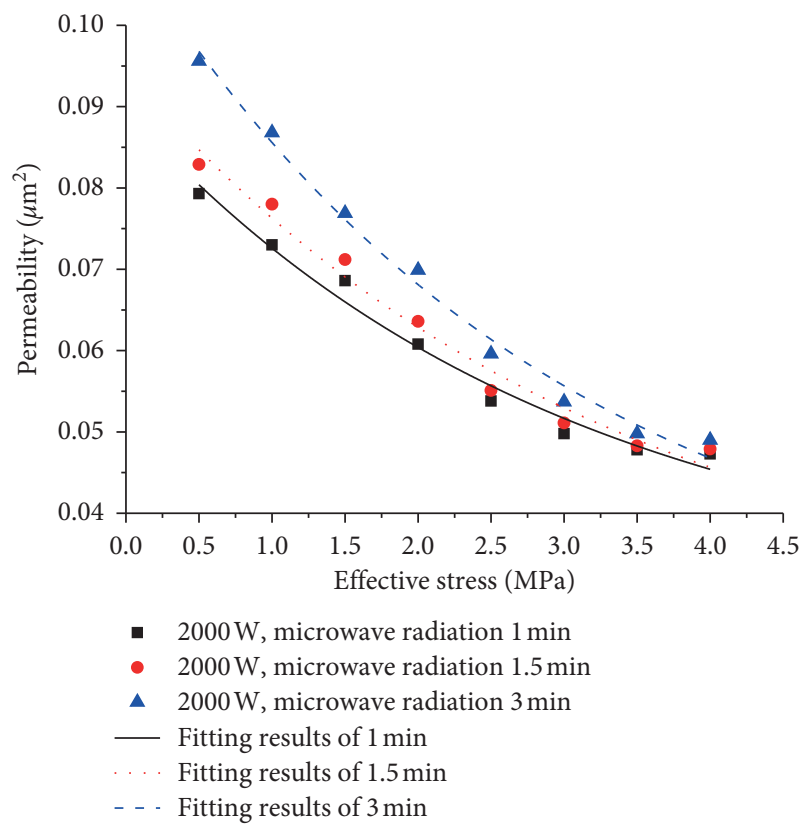

(d)

FIGURE 5: Changes in permeability with irradiation time at a confining pressure of $5 \mathrm{MPa}$.

greater than the stress generated within the specimen, and expansion was restrained, resulting in slow permeability growth. It can be concluded that reducing the effective stress in a coal-bed methane reservoir is beneficial to microwave permeability enhancement in the actual mining process.

\section{Energy Interpretation of the Microwave Effect}

4.1. Analysis of Energy Data Results. Energy data are presented in Table 6, and Figure 9 shows the change in coalsample temperature under different microwave power conditions with the same microwave energy input. With the same input energy, the required irradiation time was shortened when microwave power was increased. Figure 9(a) shows that the minimum temperature decreases as microwave power increases. Figure 9(b) shows that maximum temperature is positively correlated with microwave power, and Figure 9(c) shows that the temperature difference is also positively correlated with microwave power. Putting the three variables into one figure shows that when the same energy is input, the temperature gradient increases with rising microwave power, leading to increasing thermal stress inside the coal and resulting in drastic changes in coal structure and further expansion of pores and cracks. 
TABLE 3: Fitting results for permeability under a confining pressure of $3 \mathrm{MPa}$.

\begin{tabular}{lccc}
\hline Microwave power $(\mathrm{W})$ & Irradiation time $(\mathrm{min})$ & Fitting function & $R^{2}$ \\
\hline \multirow{3}{*}{500} & 1 & $y=0.00902 * \exp (-x / 0.81506)+0.04804$ & 0.98458 \\
& 1.5 & $y=0.01119 * \exp (-x / 0.95084)+0.04773$ & 0.98181 \\
& 3 & $y=0.01531 * \exp (-x / 0.71896)+0.0491$ & 0.95377 \\
1000 & 1 & $y=0.01255 * \exp (-x / 0.99273)+0.04811$ & 0.99116 \\
& 1.5 & $y=0.03195 * \exp (-x / 0.89326)+0.04919$ \\
1500 & 3 & $y=0.04672 * \exp (-x / 0.84715)+0.0491$ & 0.97870 \\
& 1 & $y=0.01779 * \exp (-x / 1.07753)+0.04835$ & 0.99846 \\
2000 & 1.5 & $y=0.02674 * \exp (-x / 0.97553)+0.04845$ & 0.99763 \\
& 3 & $y=0.02114 * \exp (-x / 1.39413)+0.04644$ & 0.99973 \\
& 1 & $y=0.03678 * \exp (-x / 3.13603)+0.03279$ & 0.99726 \\
\end{tabular}

TABLE 4: Fitting results for permeability under a confining pressure of $4 \mathrm{MPa}$.

\begin{tabular}{lccc}
\hline Microwave power $(\mathrm{W})$ & Irradiation time $(\mathrm{min})$ & Fitting function & $R^{2}$ \\
\hline & 1 & $y=0.01551 * \exp (-x / 1.06336)+0.04517$ & 0.99652 \\
500 & 1.5 & $y=0.02386 * \exp (-x / 2.39701)+0.03966$ & 0.99571 \\
& 3 & $y=0.03464 * \exp (-x / 2.67041)+0.03631$ & 0.99524 \\
\hline & 1 & $y=0.02088 * \exp (-x / 1.29773)+0.04475$ \\
1000 & 1.5 & $y=0.03251 * \exp (-x / 2.90559)+0.03572$ & 0.9811 \\
& 3 & $y=0.05128 * \exp (-x / 3.43043)+0.0275$ & 0.99622 \\
\hline & 1 & $y=0.0284 * \exp (-x / 1.20208)+0.04525$ & 0.98648 \\
1500 & 1.5 & $y=0.03651 * \exp (-x / 2.4433)+0.03755$ & 0.98904 \\
& 3 & $y=0.05158 * \exp (-x / 2.38764)+0.03637$ \\
\hline & 1 & $y=0.03636 * \exp (-x / 1.15447)+0.04587$ \\
& 1.5 & $y=0.0417 * \exp (-x / 1.95651)+0.04087$ & 0.99294 \\
& 3 & $y=0.06223 * \exp (-x / 2.3034)+0.03605$ & 0.9927 \\
\hline
\end{tabular}

TABLE 5: Fitting results for permeability under a confining pressure of $5 \mathrm{MPa}$.

\begin{tabular}{lccc}
\hline Microwave power $(\mathrm{W})$ & Irradiation time $(\mathrm{min})$ & Fitting function & $R^{2}$ \\
\hline \multirow{3}{*}{500} & 1 & $y=0.01305 * \exp (-x / 1.62215)+0.04209$ & 0.99704 \\
& 1.5 & $y=0.02174 * \exp (-x / 2.68395)+0.03834$ & 0.98311 \\
& 3 & $y=0.031 * \exp (-x / 2.58014)+0.03683$ & 0.99025 \\
\hline \multirow{3}{*}{1000} & 1 & $y=0.02185 * \exp (-x / 2.45422)+0.03931$ & 0.99559 \\
& 1.5 & $y=0.03195 * \exp (-x / 2.51096)+0.03731$ & 0.98382 \\
\hline & 3 & $y=0.04672 * \exp (-x / 2.99234)+0.03171$ & 0.99021 \\
1500 & 1 & $y=0.03602 * \exp (-x / 2.65327)+0.03651$ & 0.98683 \\
& 1.5 & $y=0.04662 * \exp (-x / 3.17365)+0.03143$ & 0.99161 \\
\hline & 3 & $y=0.05862 * \exp (-x / 2.58648)+0.03343$ & 0.97495 \\
& 1 & $y=0.06003 * \exp (-x / 2.99931)+0.02959$ & 0.97245 \\
& 1.5 & $y=0.06947 * \exp (-x / 3.29826)+0.02499$ & 0.98726 \\
\hline
\end{tabular}

The experimental data were processed from the perspective of energy. Figures $10(\mathrm{a})-10$ (c) show the change curves of permeability with effective stress under different microwave power conditions when the axial and confining pressures were $3 \mathrm{MPa}, 4 \mathrm{MPa}$, and $5 \mathrm{MPa}$ and the energy input remained the same. The microwave power and irradiation time were controlled to ensure the same energy input in the microwave irradiation device. Figure 10 shows that the permeability curve at $1500 \mathrm{~W}$ microwave power is obviously higher than at $500 \mathrm{~W}$ microwave power. It can be concluded that, under the action of microwaves, when the energy input to a coal sample is kept the same, choosing high power input is helpful for increasing the permeability of the coal sample.

Due to the characteristics of microwave radiation heating, changing microwave power at a given frequency does not affect the overall distribution of the microwave magnetic field, but only changes its strength. As microwave power is increased, the intensity of the microwave magnetic field and the microwave irradiation efficiency of the coal sample are enhanced. After the microwave radiation is reduced, the energy dissipates in the coal and microwave seepage enhancement is obvious. 


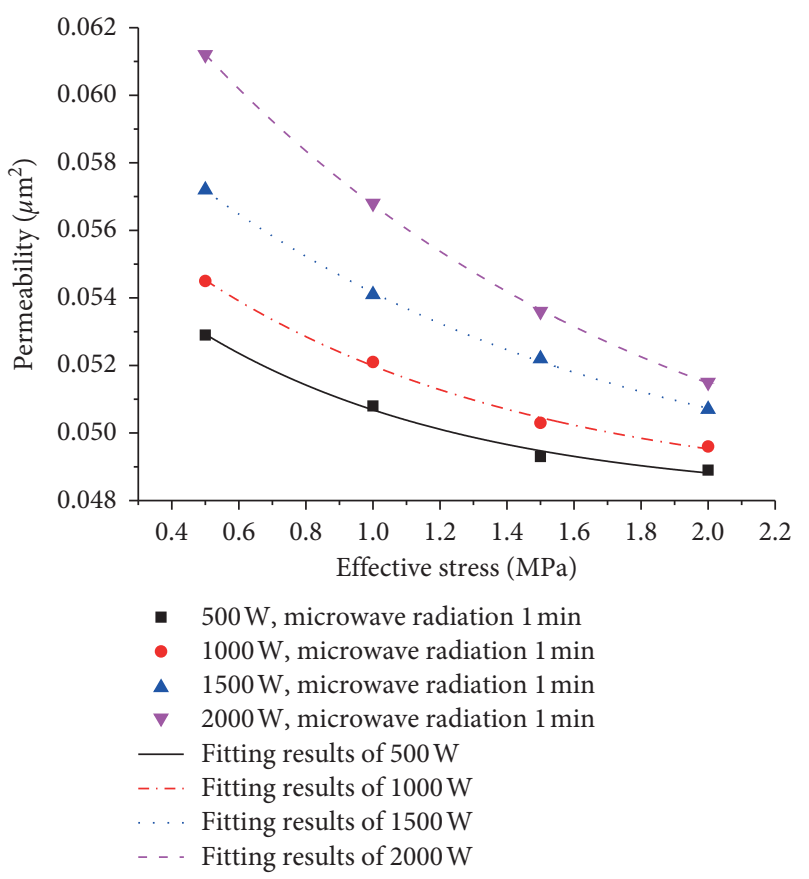

(a)

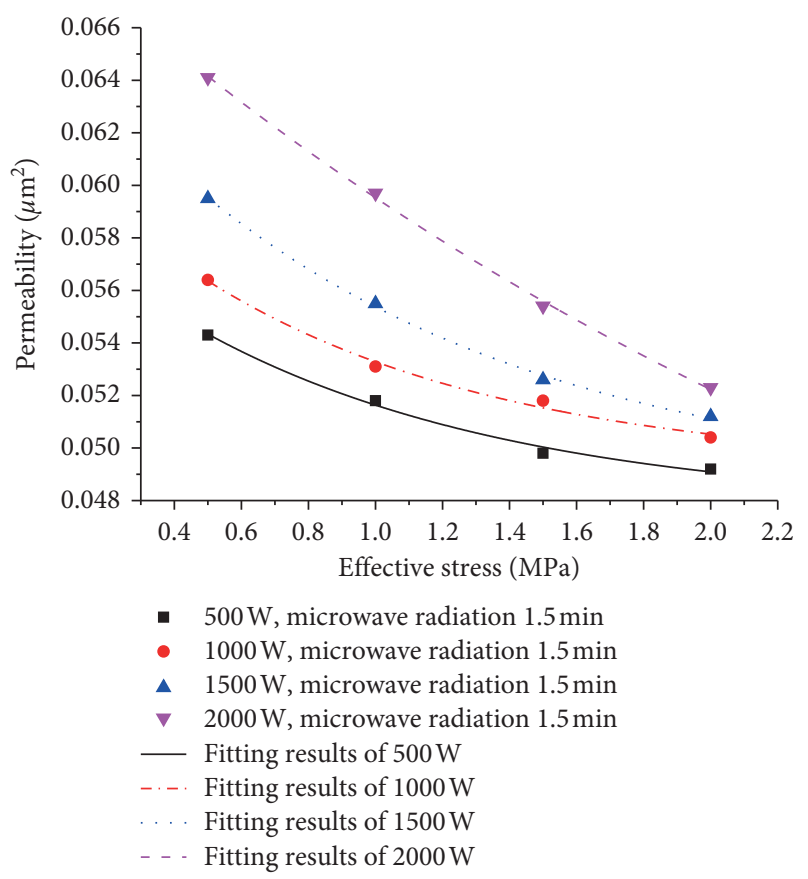

(b)

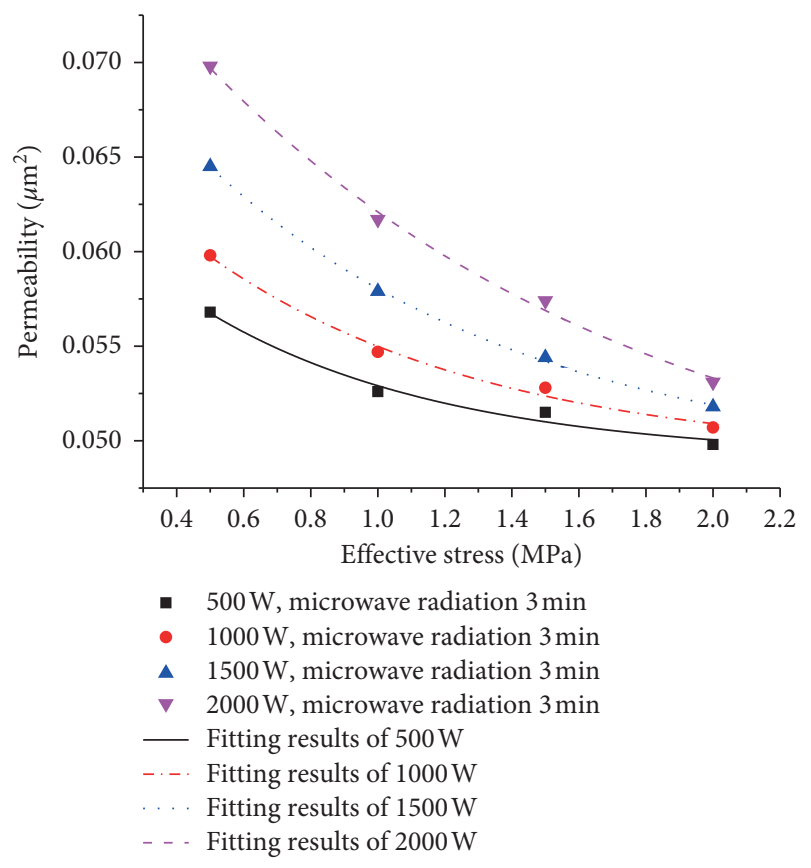

(c)

Figure 6: Effect of microwave power on permeability at a confining pressure of $5 \mathrm{MPa}$.

4.2. Energy Distribution at Different Positions in the Microwave Magnetic Field. Figure 11 shows the temperature distribution at different positions within the coal sample under different microwave powers. Figure 11(a) shows different microwave powers with the same radiation. The irradiation time was $60 \mathrm{~s}$. The 11 points in the middle section of the coal sample are distributed successively along the $x$-axis, as shown in Figure 11 . Due to the selectivity of microwave radiation, the temperature distribution was different and thermal stress was generated in the specimen, which changed the pore and fissure structure of the coal. Figure 11(a) shows that with the same irradiation time, the greater the power, the greater will be the input energy, the higher will be the peak temperature, and the greater will be the variability in the temperature distribution.

Figure 11(b) shows the distribution of temperature at different positions in the coal sample at different 


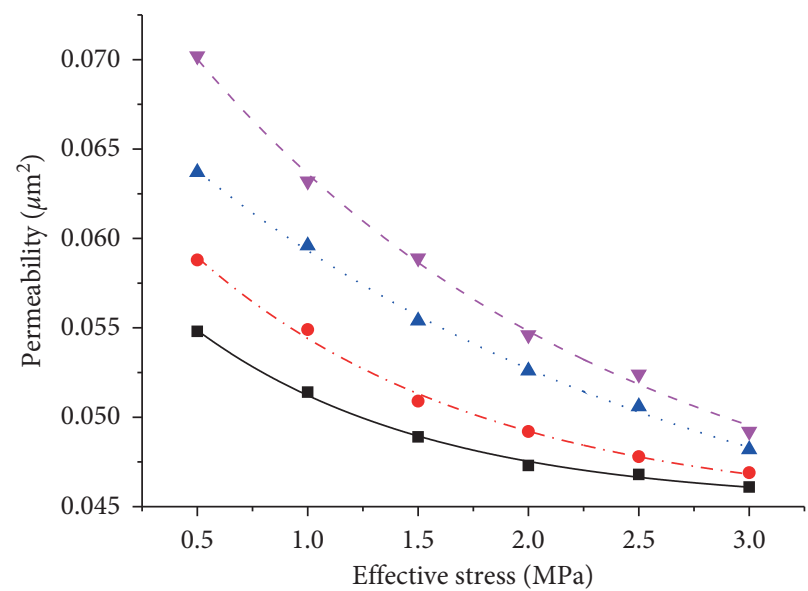

- $500 \mathrm{~W}$, microwave radiation $1 \mathrm{~min}$ - $1000 \mathrm{~W}$, microwave radiation $1 \mathrm{~min}$

- $1500 \mathrm{~W}$, microwave radiation $1 \mathrm{~min}$

$\checkmark 2000 \mathrm{~W}$, microwave radiation $1 \mathrm{~min}$

- Fitting results of $500 \mathrm{~W}$

-. . Fitting results of $1000 \mathrm{~W}$

Fitting results of $1500 \mathrm{~W}$

- - Fitting results of $2000 \mathrm{~W}$



- $500 \mathrm{~W}$, microwave radiation $1.5 \mathrm{~min}$

- $1000 \mathrm{~W}$, microwave radiation $1.5 \mathrm{~min}$

- $1500 \mathrm{~W}$, microwave radiation $1.5 \mathrm{~min}$

- $2000 \mathrm{~W}$, microwave radiation $1.5 \mathrm{~min}$

- Fitting results of $500 \mathrm{~W}$

Fitting results of $1000 \mathrm{~W}$

Fitting results of $1500 \mathrm{~W}$

Fitting results of $2000 \mathrm{~W}$

(a)

(b)

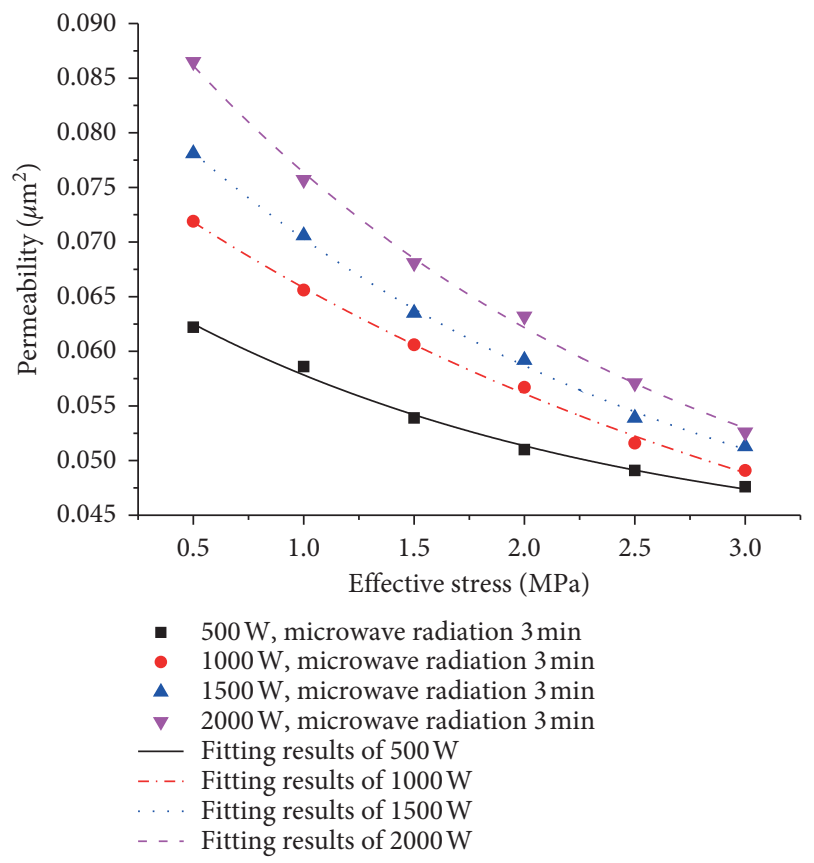

(c)

FiguRE 7: Effect of microwave power on the permeability at a confining pressure of $4 \mathrm{MPa}$.

microwave powers when the input energy remains constant. With the same energy input, the higher the microwave power, the shorter the irradiation time will be. As shown in Figure 11, due to different irradiation times, the temperature distribution at each point in the coal sample changed. However, the trend of peak temperature distribution with different powers was basically consistent with Figure 11(a). In other words, with the same energy input, the higher the power, the higher will be the peak temperature, the steeper will be the temperature gradient in the coal sample, the greater the thermal stress will be, and the more obvious the seepage enhancement effect will be on the coal sample.

4.3. Effect of Radiation Energy on Coal Permeability. The experimental data were processed from the perspective of energy. Figures 12(a)-12(c) show the change curves of permeability with effective stress under different microwave power conditions when the axial and confining 


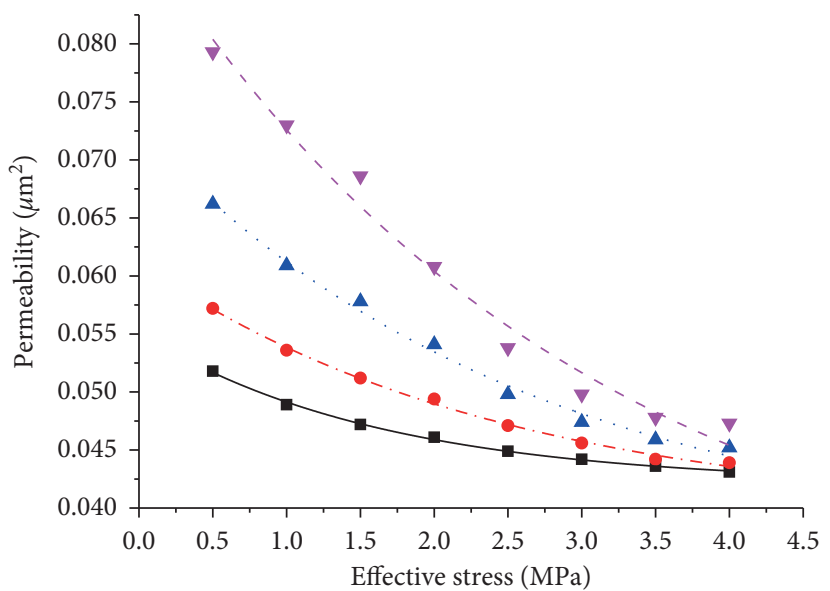

- $500 \mathrm{~W}$, microwave radiation $1 \mathrm{~min}$

- $1000 \mathrm{~W}$, microwave radiation $1 \mathrm{~min}$

- $1500 \mathrm{~W}$, microwave radiation $1 \mathrm{~min}$

$\checkmark 2000 \mathrm{~W}$, microwave radiation $1 \mathrm{~min}$

- Fitting results of $500 \mathrm{~W}$

-.. Fitting results of $1000 \mathrm{~W}$

Fitting results of $1500 \mathrm{~W}$

- - Fitting results of $2000 \mathrm{~W}$

(a)

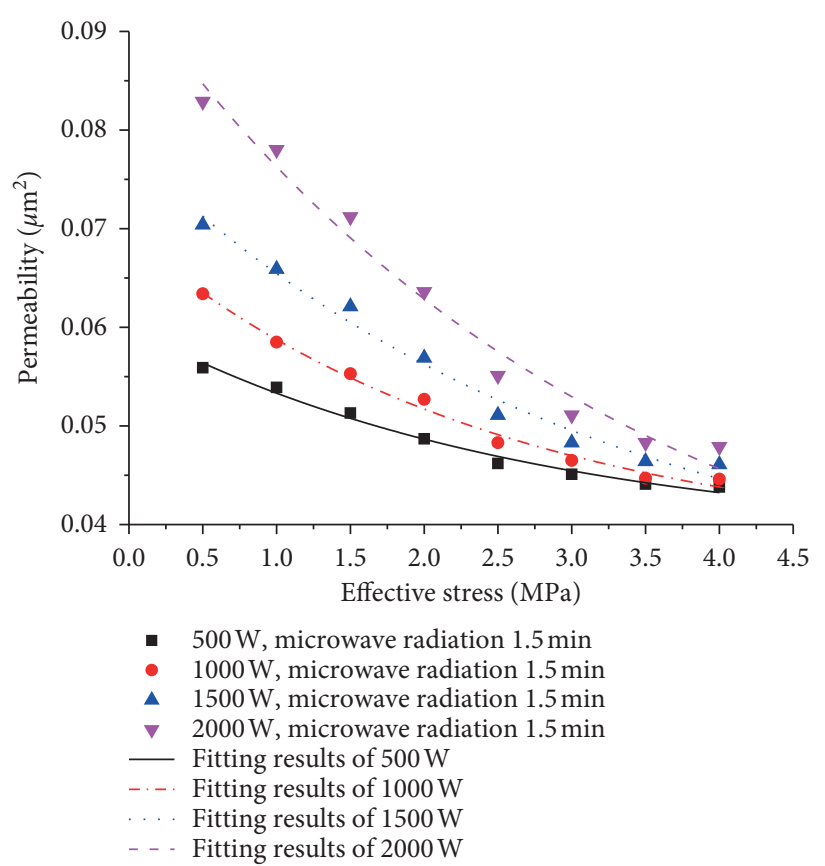

(b)

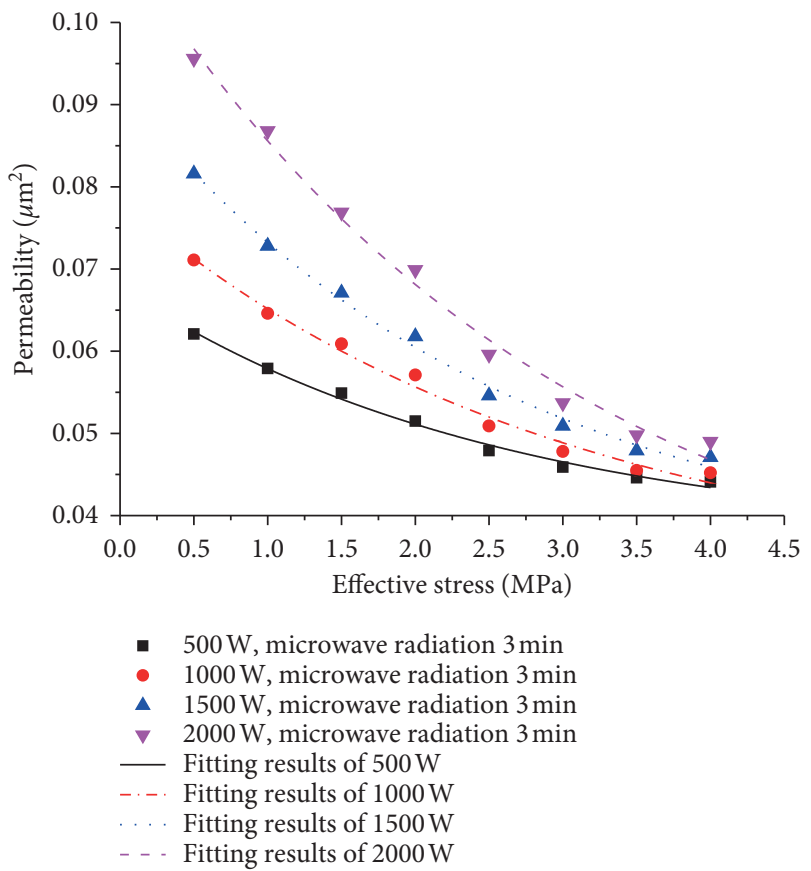

(c)

FIGURE 8: Effect of microwave power on the permeability at a confining pressure of $5 \mathrm{MPa}$.

pressures were $3 \mathrm{MPa}, 4 \mathrm{MPa}$, and $5 \mathrm{MPa}$ and when the energy input remained constant. The microwave power and irradiation time were controlled to ensure the same energy input in the microwave irradiation device. Figure 12 shows that the permeability curve at $1500 \mathrm{~W}$ microwave power is obviously higher than at $500 \mathrm{~W}$ microwave power. It can be concluded that under the action of microwaves and under constant coal sample energy input, choosing high power input is helpful to increase the permeability of the coal sample.
Due to the characteristics of microwave radiation heating, changing the power of microwaves at the same frequency does not affect the overall distribution of the microwave magnetic field, but only changes its strength. As microwave power was increased, the intensity of the microwave magnetic field and the microwave irradiation efficiency of the coal sample were enhanced. After the microwave radiation was reduced, the energy dissipated in the coal, and the microwave seepage enhancement effect was obvious. 
TABLE 6: Variation trend of temperature under different microwave power.

\begin{tabular}{lcccc}
\hline Microwave power $(\mathrm{W})$ & Irradiation time $(\mathrm{s})$ & Maximum temperature $\left({ }^{\circ} \mathrm{C}\right)$ & Minimum temperature $\left({ }^{\circ} \mathrm{C}\right)$ & Temperature difference $\left({ }^{\circ} \mathrm{C}\right)$ \\
\hline 500 & 120 & 87.865 & 18.332 & 69.533 \\
1000 & 60 & 98.282 & 16.277 & 82.005 \\
1500 & 40 & 102.34 & 14.826 & 87.514 \\
2000 & 30 & 104.79 & 13.972 & 90.818 \\
\hline
\end{tabular}

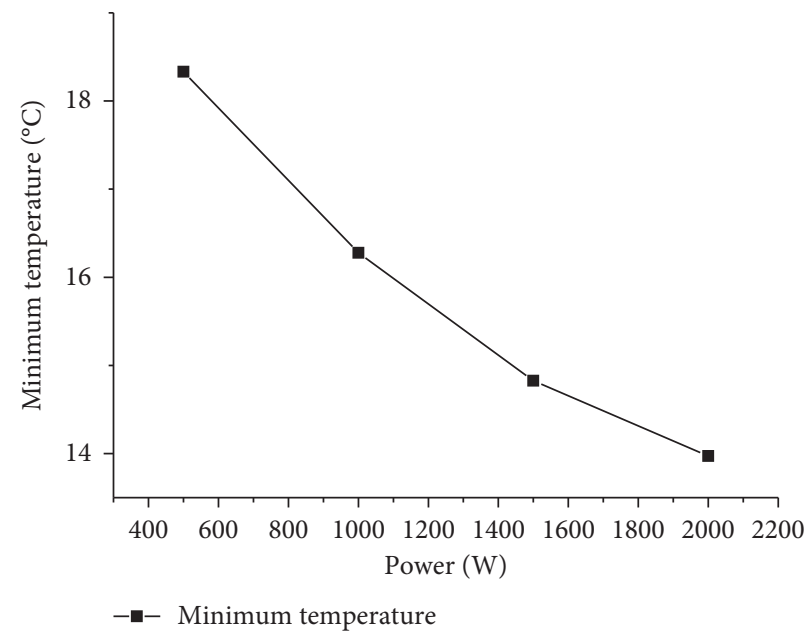

(a)

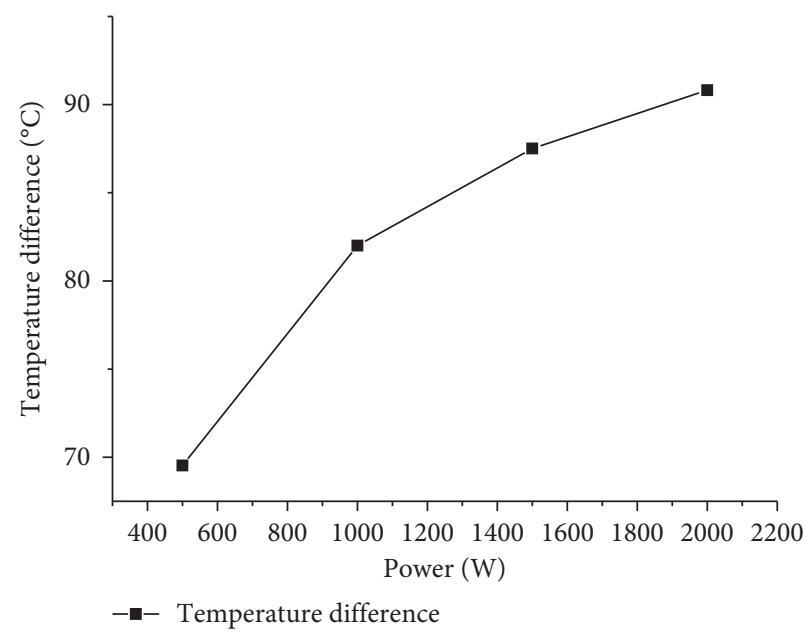

(c)

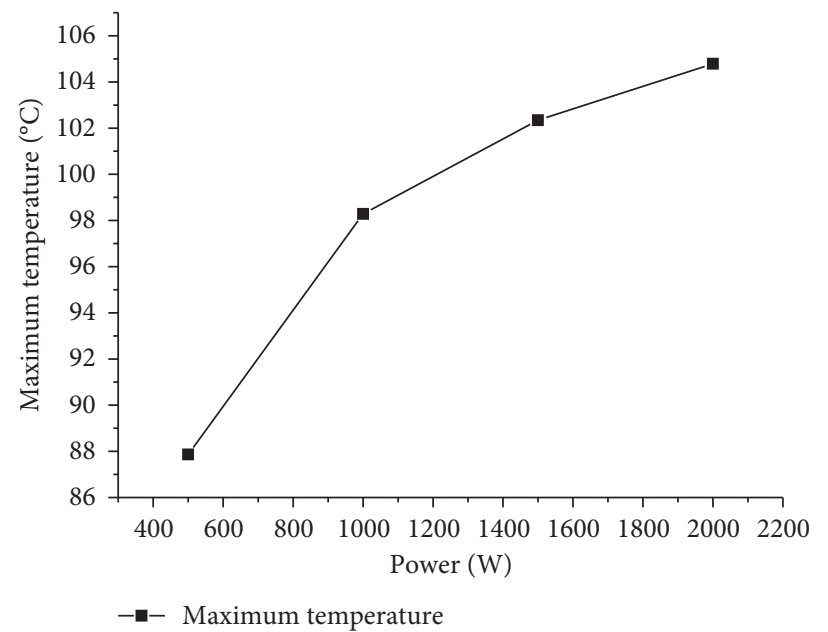

(b)

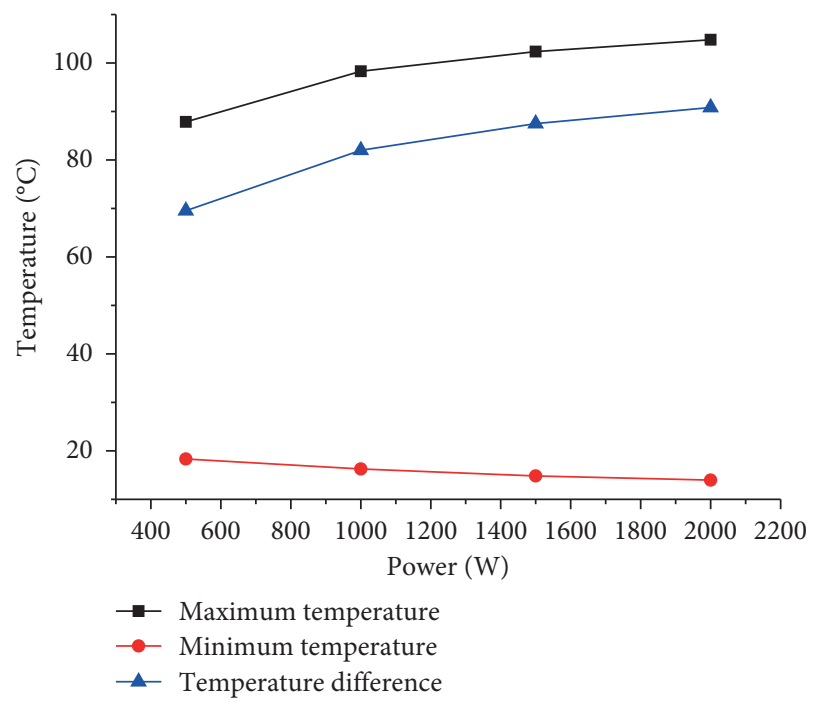

(d)

FIGURE 9: Comparison of microwave magnetic field temperature with the same energy input.

\section{Discussion}

5.1. Comprehensive Analysis of the Effect of Microwave Radiation on Coal Permeability. To consider comprehensively the influence of microwave action conditions on permeability, three-dimensional surface graphs of permeability varying with various factors were drawn. The processing results are shown in Figures 13-15. The figure depicts the three-dimensional spatial surface relation of permeability and microwave power, permeability and effective stress, and permeability and duration of microwave action. The variation of the permeability of coal samples under the influence of various factors can be clearly seen in the figures.

Figures 13-15 compare the three-dimensional curved surface of the permeability of coal samples with different microwave irradiation durations in a single graph for comparative analysis. The graph reveals that under constant axial and confining pressures and fixed microwave conditions, lowering the effective stress causes the pore pressure inside the coal body to increase, and the gas accelerates the seepage flow from the inside of the coal body under a large pressure difference. Therefore, reducing the effective stress 


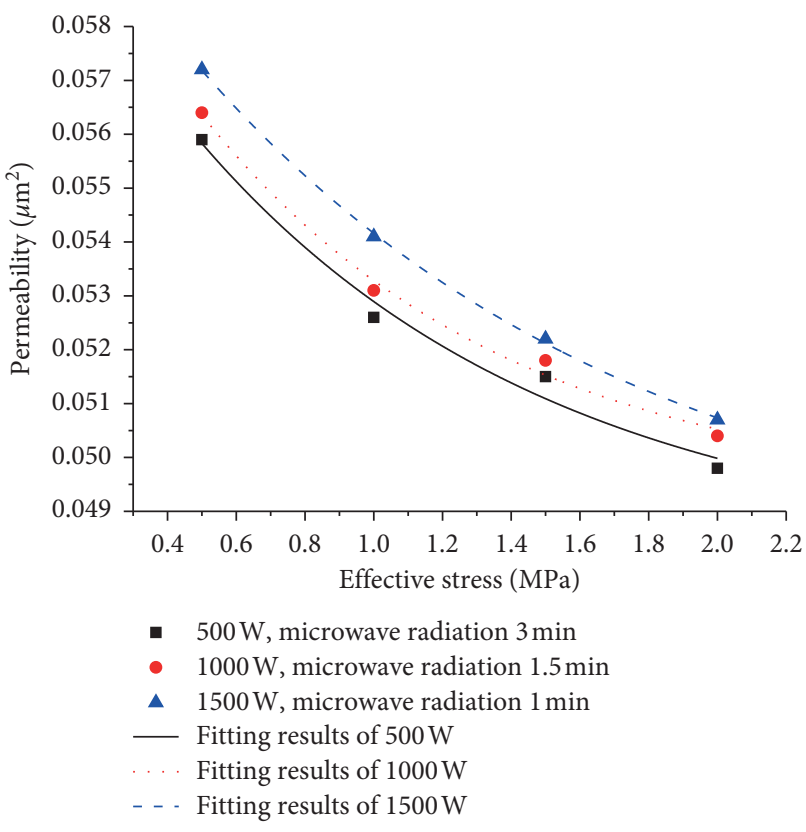

(a)

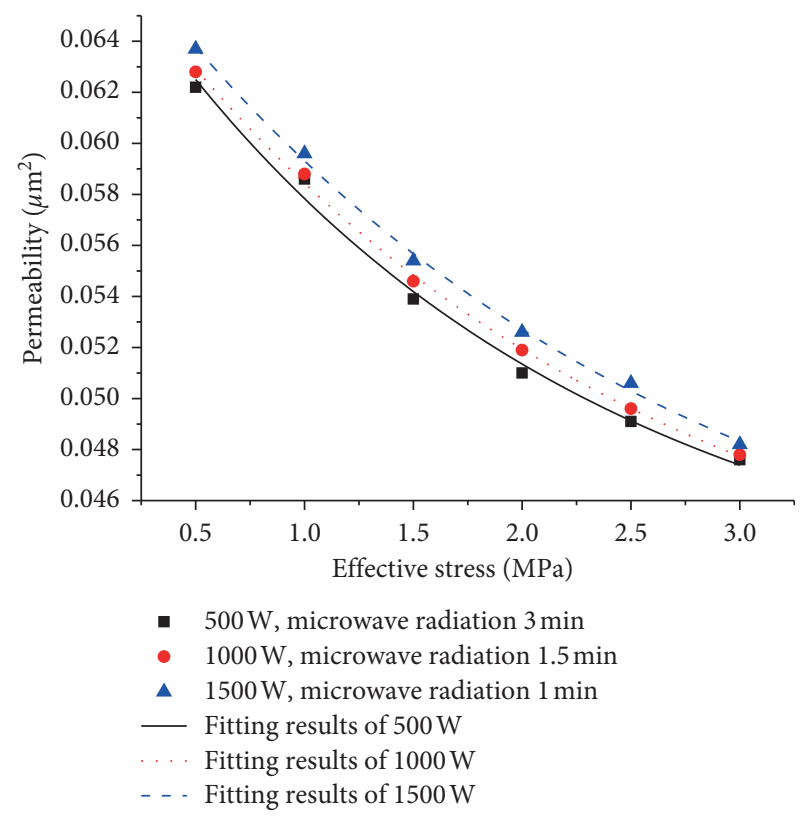

(b)

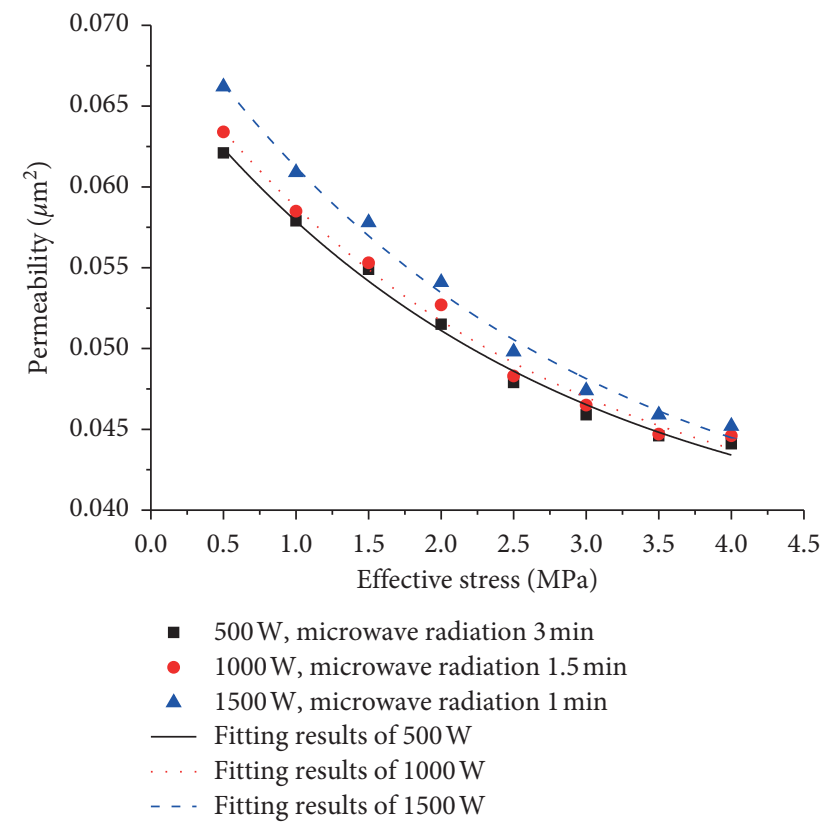

(c)

FIGURE 10: Variation trends of permeability with the same energy input and different axial and confining pressures.

in the environment of a coal body is conducive to increasing coal permeability under microwave radiation. After the microwave power has been increased, the field strength of the microwave electromagnetic field increases, and the mineral absorption in the coal increases. When certain substances absorb more microwave power, their temperature rises rapidly, leading to an increase in the internal temperature gradient of the coal body; this uneven temperature distribution causes thermal stress inside the coal body. Under the action of microwaves, the coal body suffers secondary damage due to internal thermal stress, the porefracture structure expands again, the number of gas migration channels increases, and gas migration is accelerated. Therefore, coal permeability is positively correlated with microwave power. In consequence, reducing the effective stress of the coal seam within a certain range, increasing the microwave power, and increasing the action time are beneficial to improving the permeability of coal samples under the action of microwaves.

5.2. Mechanical Relation of Coal Permeation Enhancement after Microwave Irradiation. In the previous section, data from coal seepage experiments under microwave irradiation 


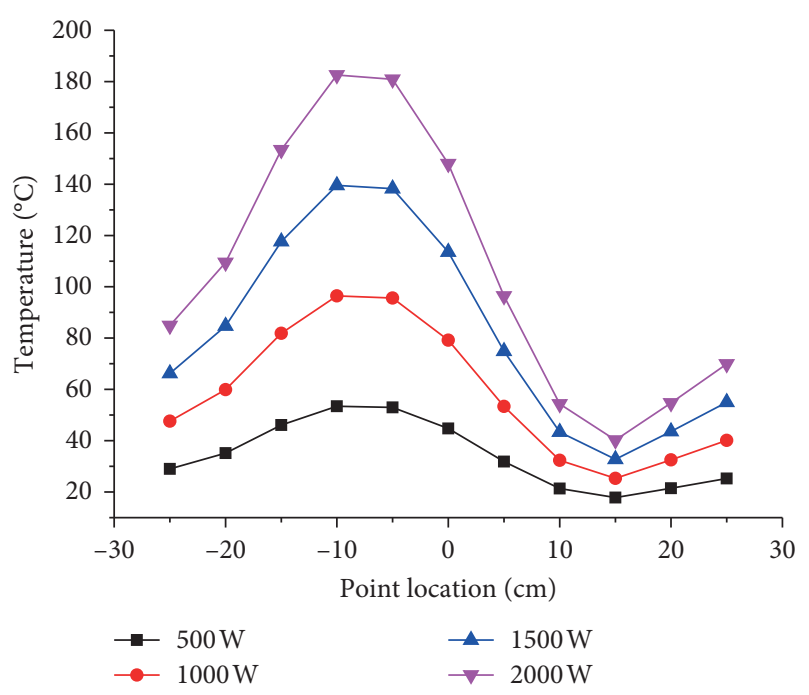

(a)

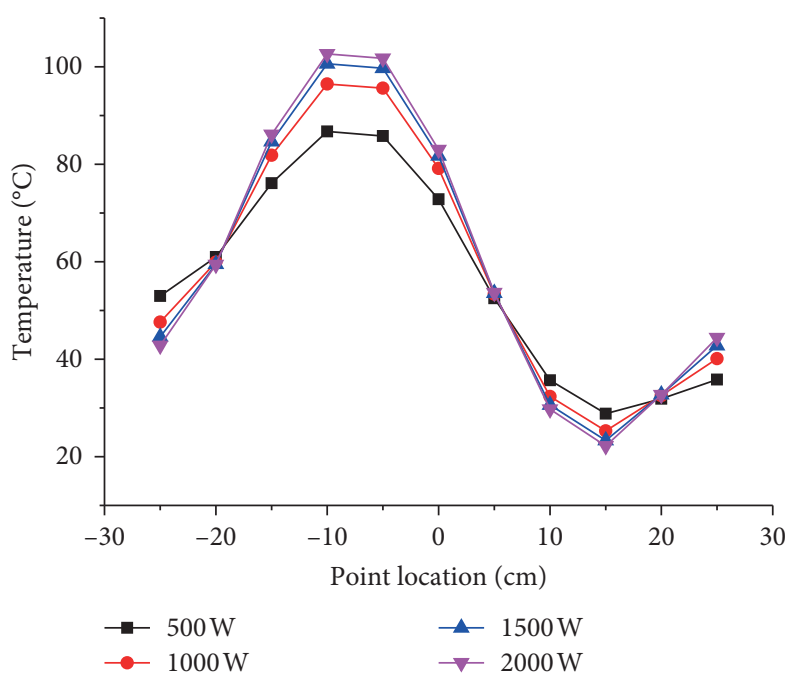

(b)

FIGURE 11: Distribution of temperature at different positions in the coal sample. Different microwave powers with (a) the same irradiation time and (b) the same input energy.

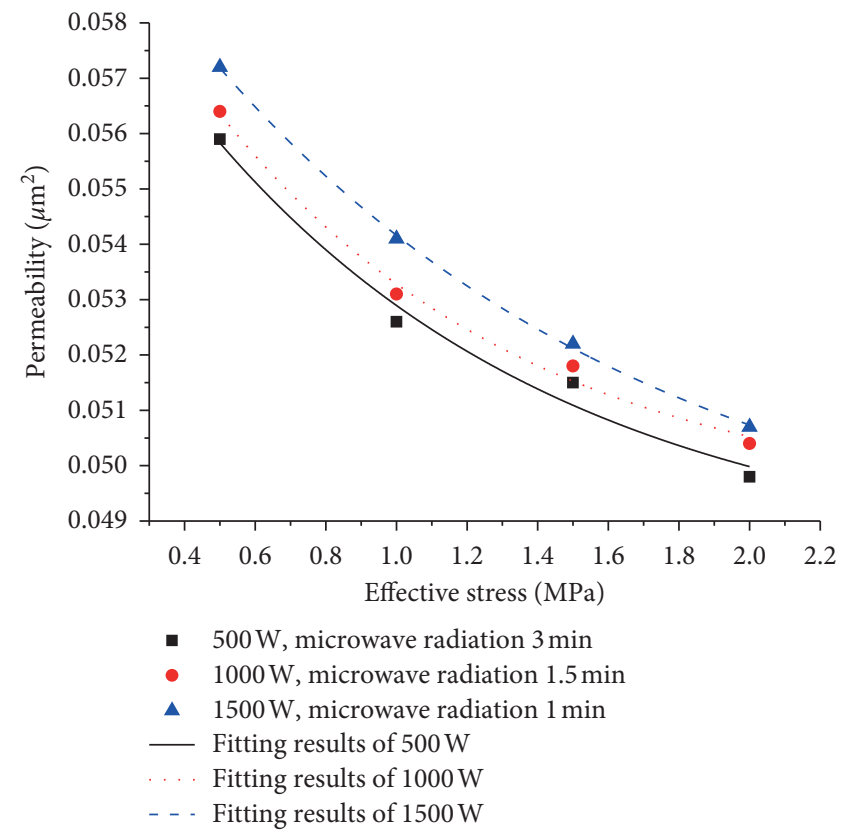

(a)

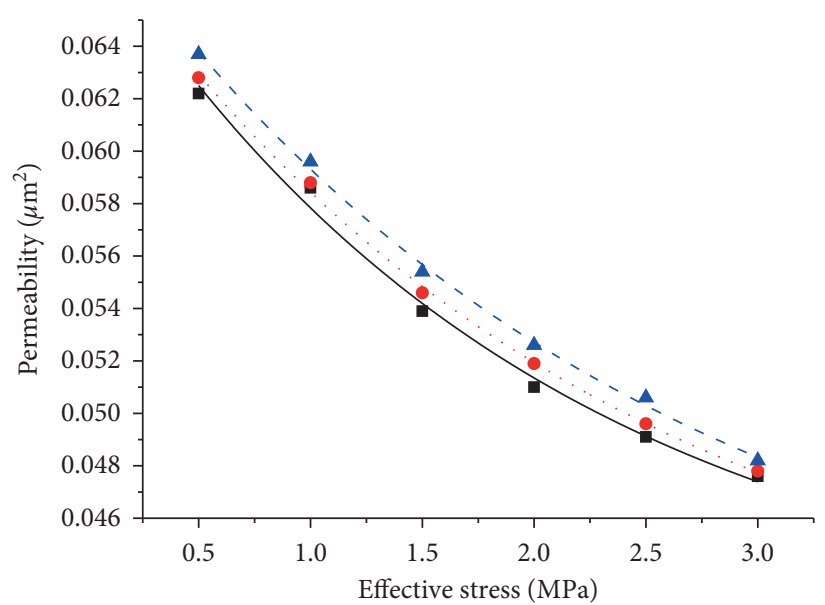

- $500 \mathrm{~W}$, microwave radiation $3 \mathrm{~min}$

- $1000 \mathrm{~W}$, microwave radiation $1.5 \mathrm{~min}$

- $1500 \mathrm{~W}$, microwave radiation $1 \mathrm{~min}$

_ Fitting results of $500 \mathrm{~W}$

Fitting results of $1000 \mathrm{~W}$

- - Fitting results of $1500 \mathrm{~W}$

(b)

Figure 12: Continued. 




(c)

FIGURE 12: Variation trends of permeability with the same energy input.



FIgURE 13: Three-dimensional changes of permeability under axial and confining pressures of $3 \mathrm{MPa}$.

were analyzed. It can be concluded that under microwave radiation, the macroscopic permeability of coal samples is positively correlated with microwave irradiation time and microwave power. With improvement of the microwave action conditions, an increment $\Delta K$ in coal permeability is obtained, and coal permeability is improved.

By analyzing the experimental data of the seepage experiment with the coal sample under the action of microwave radiation and by comprehensively considering influential factors such as effective stress and microwave effect, it has been found that the influence of microwave radiation on the permeability of a coal sample can be characterized by an exponential function. The expression of the exponential function is as follows:

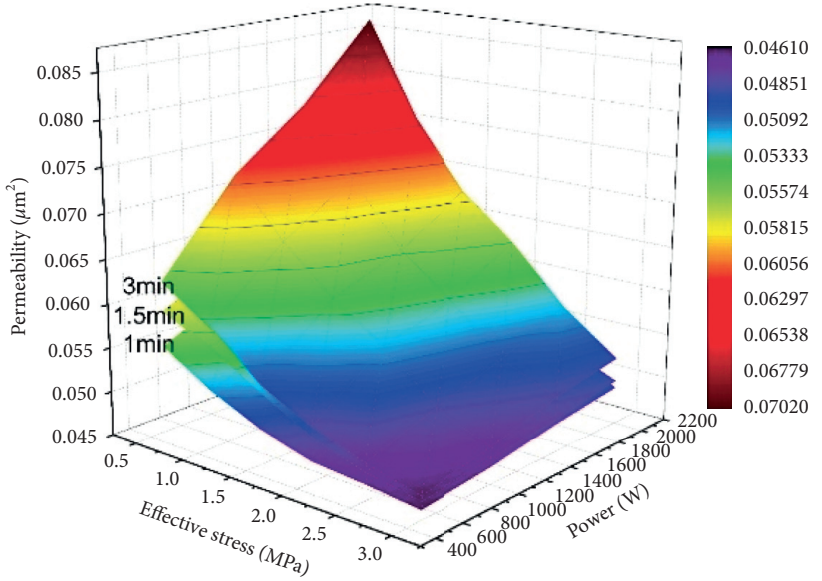

FIgURE 14: Three-dimensional changes of permeability under axial and confining pressures of $4 \mathrm{MPa}$.

$$
K=\zeta K_{0}\left(\frac{\varphi}{\varphi_{0}}\right)^{x}=\zeta K_{0} e^{-x \eta \sigma_{i j}},
$$

where $K$ is the coal sample permeability; $K_{0}$ is the initial permeability of the coal sample; $\varphi$ is the coal sample porosity; $\varphi_{0}$ is the initial porosity of the coal sample; $x$ is the material parameter, here set to 3 ; $\eta$ is the porosity change coefficient; $\sigma_{i j}$ is the effective stress; and $\zeta$ is the response coefficient of the coal-rock structure to microwave radiation:

$$
\zeta=\Delta d c_{m} Q \frac{1}{j}=t P \frac{1}{F} c_{m} Q \frac{1}{j},
$$

where $\Delta d$ is the increment of coal structure, $\mu \mathrm{m}$; $t$ is effect time of microwave, $\min ; P$ is the power of microwave, $\mathrm{W} ; F$ 


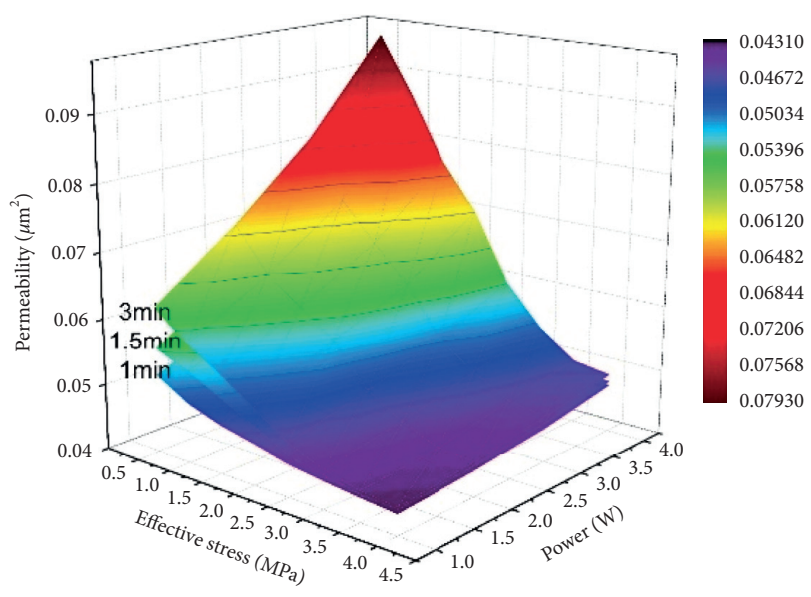

FIGURE 15: Three-dimensional changes of permeability under axial and confining pressures of $5 \mathrm{MPa}$.

is Structural closing force, $\mathrm{N}$; $Q$ is thermal stress after microwave affection, $\mathrm{MPa}^{-1}$; and $j$ is structural size of coal seam, $m$.

Through comprehensive analysis of micro- and macro experiments, it was concluded that the structural response coefficient $\zeta$ of the coal-rock mass under microwave radiation is directly related to the structural size increment $\Delta d$ of the coal-rock mass and the stress environment. The increment $\Delta d$ of the coal-rock structure size is also related to the microwave power $\mathrm{W}$, the microwave action time $t$, the field intensity $E$ of the microwave electromagnetic field, coal-rock stress sensitivity, coal matrix shrinkage, coal-rock mineral composition, and other factors. When the stress environment of the coal-rock structure is constant, the effect of microwave radiation on the coal structure is $\Delta d$, which leads to a change in the structural response coefficient $\zeta$ of the coal-rock structure under the action of microwave radiation. After improving the action conditions of microwave irradiation, the value of $\zeta$ increases and the permeability of the coal sample also increases.

\section{Conclusions}

The key to coal-bed methane exploitation lies in promoting solution and increasing permeability. Microwave radiation is a kind of enhanced heat injection and extraction method. Compared with the heat conduction of conventional heating, the heating of coal by microwave radiation is considered to be a process in which high-frequency electromagnetic fields drive high-frequency oscillations of polar molecules inside coal rocks, and intense friction generates heat between molecules. Therefore, microwave radiation heats up rapidly and covers a wide range, which is conducive to the formation of coal-bed methane desorption and seepage channels. In this experiment, the dynamic law of desorption, diffusion, and permeability of coal under stress under real-time action of microwave was carried out. Through comparative analysis of the experimental data, the following conclusions can be drawn:

(1) Under given axial pressure, confining pressure, and effective stress, microwaves with different power were used to irradiate the coal sample for the same time. The higher the microwave power used, the higher the coal sample permeability became, or in other words, the increase in coal sample permeability was positively correlated with the microwave power used. Under a certain fixed stress condition, the same energy was input to the coal sample by the microwave generator. The permeability of the coal sample was found to be higher when high power was selected. The increment in coal sample permeability under different power conditions was relatively small, but sufficient to show that using higher power within a certain range is conducive to improving coal sample permeability.

(2) By analyzing the experimental data, it was found that, under certain confining and axial pressures, the increment of change in coal sample permeability with microwave action was different under different effective stress conditions. In the high-effectivestress area, the growth rate of coal sample permeability was lower than in the low-effective-stress area, and in that area, it was more beneficial to improve the efficiency of increasing microwave permeability. Therefore, the efficiency of microwave irradiation stimulation can be improved by reducing the effective stress of a coal reservoir in the actual mining process.

(3) With the same microwave energy input, the minimum temperature of the coal sample decreased and the maximum temperature increased as microwave power was increased. Moreover, with increasing microwave power, the temperature differences in the coal-sample temperature field tended to increase. By analyzing the temperature distribution of coal samples, it was found that the higher the microwave power selected, the higher was the peak temperature value of coal samples irradiated for the same time. Moreover, with the same energy input, the higher the microwave power selected, the higher became the peak temperature value of the coal-sample temperature field.

\section{Data Availability}

All data used to support the study are present in the article as figures or tables.

\section{Conflicts of Interest}

The authors declare that they have no conflicts of interest.

\section{Acknowledgments}

This study was supported by the National Natural Science Foundation of China (grant no. 51574138), the Basic Research and Strategic Reserve Technology Research Fund Project of CNPC (grant no. 2018D-500807), and the Liaoning Provincial Department of Education General Project (grant no. LJYL046). The authors sincerely thank the 
anonymous reviewers for improving the quality of article. The authors would also like to thank NSFC, CNPC, and Department of Education in Liaoning Province for providing funds. The authors thank International Science Editing (http://www.internationalscienceediting.com) for language editing this manuscript.

\section{References}

[1] M. Geng, H. Chen, Y. Chen et al., "Methods and results of the fourth round national CBM resources evaluation," Coal Science and Technology, vol. 46, no. 6, pp. 64-68, 2018.

[2] D. Zhang, J. Zhu, X. Zhao et al., "Dynamic assessment of coalbed methane resources and availability in China," Journal of China Coal Society, vol. 43, no. 6, pp. 1598-1604, 2018.

[3] S. Long, X. Li, L. Ye et al., "Comparison and enlightenment of coal bed methane geology at home and abroad," Oil \& Gas Geology, vol. 35, no. 5, pp. 696-703, 2014.

[4] D. Li, X. Gao, Z. Liu et al., "Comparison and revelation of coalbed methane resources distribution characteristics and development status between China and America," Coal Science and Technology, vol. 46, no. 1, pp. 252-261, 2018.

[5] C. Ai, X.-X. Li, J. Zhang, D. Jia, and W.-J. Tan, "Experimental investigation of propagation mechanisms and fracture morphology for coalbed methane reservoirs," Petroleum Science, vol. 15, no. 4, pp. 815-829, 2018.

[6] D. Zhao, T. Gao, Y. Ma, and Z. Feng, "Methane desorption characteristics of coal at different water injection pressures based on pore size distribution law," Energies, vol. 11, no. 9, p. 2345, 2018.

[7] D. Zhao, D. Li, Y. Ma et al., "Experimental study on methane desorption from lumpy coal under the action of hydraulic and thermal," Advances in Materials Science and Engineering, vol. 2018, Article ID 3648430, 10 pages, 2018.

[8] C. Wu and X. Zhang, "Morphology and propagation of hydraulic fractures for CBM wells," Acta Geologica Sinica-English Edition, vol. 91, no. 5, pp. 1936-1937, 2017.

[9] T. T. Jiang, J. H. Zhang, and H. Wu, "Effects of fractures on the well production in a coalbed methane reservoir," Arabian Journal of Geosciences, vol. 10, no. 22, 2017.

[10] Z. Fang, X. Li, H. Chen et al., "Feasibility study of gas mixture enhanced coalbed methane recovery technology," Rock and Soil Mechanics, vol. 31, no. 10, pp. 3223-3229, 2010.

[11] K. Sun, A. Li, S. Zhang et al., "Experimental study on permeability changing regularity of the non-supercritical $\mathrm{CO}_{2}$ replacing and exploiting $\mathrm{CH}_{4}$ under THM coupling action," Journal of Safety and Environment, vol. 13, no. 2, pp. 182-186, 2013.

[12] G. Yu, Z. H. A. I. Cheng, L. Qin et al., "Changes to coal pores by ultrasonic wave excitation of different powers," Journal of China University of Mining \& Technology, vol. 47, no. 2, pp. 264-270+322, 2018.

[13] L.-J. Zhao and Y. Qin, "Experiment on improving the permeability of coal reservoir under ultrasound," Natural Gas Geoscience, vol. 25, no. 5, pp. 747-752, 2014.

[14] Y.-D. Jiang, S. Xiao, C. Yue-zhen et al., "Characteristics of methane desorption and diffusion on coal under acoustic wave," Journal of China Coal Society, vol. 40, no. 3, pp. 623-628, 2015.

[15] Z. Feng and Z. Wan, "Methane release under triaxial stressed coal at high temperature and its application in methane extracting by heat injection," Journal of Mining \& Safety Engineering, vol. 35, no. 2, pp. 442-448, 2018.
[16] F. Zhang, Y. Wu, B. Mao et al., "Coupled thermal-hydrological-mechanical analysis of exploiting coal methane by heat injection," Journal of Mining \& Safety Engineering, vol. 29, no. 4, pp. 505-510, 2012.

[17] L. I. Li, W. Liang, Z. Li et al., "Experimental investigation on enhancing coalbed methane recovery bu injecting high temperature $\mathrm{CO}_{2}$," Journal of China Coal Society, vol. 42, no. 8, pp. 2044-2050, 2017.

[18] Y.-l. Zhu, Y.-b. Tian, Y.-m. Qin et al., “Application progress of the microwave technology in petrochemical industry," Contemporary Chemical Industry, vol. 43, no. 5, pp. 870-872+886, 2014.

[19] S. H. Ju, P. Singh, and J. H. Peng, "Recent developments in the application of microwave energy in process metallurgy at KUST," Mineral Processing and Extractive Metallurgy Review, vol. 29, no. 3, pp. 181-190, 2018.

[20] X. Peng, G. Jian, and Y. Liu, "Application of microwave technology in coal processing and utilization process," Chemical Enterprise Management, no. 32, pp. 220-221, 2018.

[21] Y.-d. Hong, B.-q. Lin, H. C.-j. Li et al., "Influence of microwave energy on fractal dimension of coal cores: implications from nuclear magnetic resonance," Energy \& Fuels, vol. 30, no. 12, pp. 10253-10259, 2016.

[22] Y.-d. Hong, B.-q. Lin, H. Li, H.-m. Dai, C.-j. Zhu, and H. Yao, "Three-dimensional simulation of microwave heating coal sample with varying parameters," Applied Thermal Engineering, vol. 93, pp. 1145-1154, 2016.

[23] Y.-d. Hong, B.-q. Lin, and H. C.-j. Li, "Effect of microwave irradiation on petrophysical characterization of coals," Applied Thermal Engineering, vol. 102, pp. 1109-1125, 2016.

[24] L. Ge, Y. Zhang, Z. Wang, J. Zhou, and K. Cen, "Effects of microwave irradiation treatment on physicochemical characteristics of Chinese low-rank coals," Energy Conversion and Management, vol. 71, pp. 84-91, 2013.

[25] Z. Wang, L. I. Ning, J. Wei et al., "Experimental study on response characteristics of gas desorption in coal under effect of discontinuous microwave loading," Journal of Safety Science and Technology, vol. 13, no. 4, pp. 76-80, 2017.

[26] H. Yu, X. Cui, and R. Zhang, "Experimental research on effect of microwave radiation on gas desorption characteristics of coal particle," Journal of Safety Science and Technology, vol. 13, no. 10, pp. 25-29, 2017. 